The Journal of Mathematical Sociology

\title{
Who controls the controller? A dynamical model of corruption
}

\section{Elvio Accinelli, Filipe Martins, Jorge Oviedo, Alberto Pinto \& Luis Quintas}

To cite this article: Elvio Accinelli, Filipe Martins, Jorge Oviedo, Alberto Pinto \& Luis Quintas (2017) Who controls the controller? A dynamical model of corruption, The Journal of Mathematical Sociology, 41:4, 220-247, DOI: 10.1080/0022250X.2017.1388235

To link to this article: https://doi.org/10.1080/0022250X.2017.1388235

\section{曲 Published online: 13 Nov 2017.}

Submit your article to this journal




\title{
Who controls the controller? A dynamical model of corruption
}

\author{
Elvio Accinellia, Filipe Martins ${ }^{b}$, Jorge Oviedo ${ }^{c}$, Alberto Pinto ${ }^{b}$, and Luis Quintas ${ }^{c}$ \\ aFacultad de Economía, Universidad Autónoma de San Luis Potosí, San Luis Potosí, México; 'bepartamento de \\ Matemática, Universidade de Porto, Porto, Portugal; ' Instituto de Matemática Aplicada, Universidad Nacional de San \\ Luis and CONICET, San Luis, Argentina
}

\begin{abstract}
The aim of this article is to give at least a partial answer to the question made in the title. Several works analyze the evolution of the corruption in different societies. Most of such papers show the necessity of several controls displayed by a central authority to deter the expansion of the corruption. However there is not much literature that addresses the issue of who controls the controller. This article aims to approach an answer to this question. Indeed, as it is well known, in democratic societies an important role should be played by citizens. We show that politically active citizens can prevent the spread of corruption. More precisely, we introduce a game between government and officials where both can choose between a corrupt or honest behavior. Citizens have a political influence that results in the prospects of a corrupt and a non-corrupt government be re-elected or not. This results in an index of intolerance to corruption. We build an evolutionary version of the game by means of the replicator dynamics and we analyze and fully characterize the possible trajectories of the system according to the index of intolerance to corruption and other relevant quantities of the model.
\end{abstract}

\section{KEYWORDS}

Corruption; game theory; evolutionary theory; dynamical stability

\section{Introduction}

In February 2014, the European Union published its first ever anti-corruption report. Over 41 pages, it concluded that bribery, tax evasion, cronyism, embezzlement, political fraud, and the like, cost the European economy 120 billion euros at year, just short of the EU annual budget. Corruption is costly, but it deprives citizens of more than money. There is a lot of empirical and theoretical evidence showing that high and rising corruption increases income inequality and poverty.

In this article we conclude that citizens are key in the fight against corruption, because in a democratic country they have the possibility to exert pressure demanding the government to combat this scourge.

There is a profuse economic literature related with the topic of administrative and political corruption. Pioneering works in the area are Rose-Ackerman (1975) and Rose-Ackerman (1978). A basic insight that emerges from many studies is the self-enforcing nature of corruption: in an environment where corruption is the norm, corruption tends to persist and to be imitated, see for instance Lui (1985) Lui (1986); Sah (1987); Mishra (2006). In recent works the evolution of the corruption in a given society is modeled using the evolutionary game theory. Even when initially individuals choice their strategies independently, after some time, they compare the obtained payoffs and copy the apparently more profitable strategy. Under this evolutionary approach and under given social conditions, corruption, can become a dominant strategy. See for instance Accinelli and Sánchez Carrera $(2012,2015)$. In much of this literature the conditions under which the public 
officials are willing to be corrupted are analyzed. These officials must ensure compliance with the law, payment of taxes by citizens, compliance with rules aimed at preventing pollution, and annoying sounds. But, often, officials themselves are willing to accept bribes from citizens who do not want to be punished for breaching the rules of coexistence. See for instance Accinelli, Policardo, \& Sánchez Carrera (2014). The increasing of official corruption, in turn, creates incentives for the development of the corrupt behavior and in this way the society as a whole becomes corrupt. The question about how to avoid the evolution of corruption is not easy to be answered however of the great importance.

On the other hand, in many specialized papers it is considered that the central authority, the government, and or central agencies should play an important role to deterrence and to control the evolution of corruption. The government is considered as a benevolent planner trying to maximize the social welfare. But many times, individuals who are members of these central agencies (political elites) can benefit by the evolution of corruption among officials. In such cases these agents act maximizing their own selfish interests rather than being compliant agents maximizing the social welfare. Models of this behavior are considered for instance in Becker (1983) and Grossman and Helpman (1994), but the question that remains unanswered is: who and how controls the controller?

An interesting discussion on this point is introduced in Hurwicz (2007). In the cited work, the author retakes a question posed by the Latin author Juvenal: Quis custodiet ipsos custodes?" This is a Latin locution variously translated as "Who will guard the watchmen?", "Who will guard the guards?", or "Who will guard the guards themselves?" Originally the problem was posed by Plato in the Republic (Plato) in his work on government and morality, to control the ones who exercise positions of power. The perfect society, as described by Socrates, is based on workers, slaves, and merchants. The guard class is to protect the city. The question before Socrates is "who will keep the guardians?" Or "who will protect us from the protectors?" Plato's answer to this question is that they will take care of themselves. According to Plato it would suffice for the guard to perform their function with honesty, to make them believe that they are better than those to whom they render their service and that therefore it is his responsibility to watch and to protect the inferiors. The Latin quotation is attributed to Juvenal written in his work Satires (written five centuries after Plato) (see (Juvenal, 1991)). In that work he referred to the inability to control the marital fidelity (Satire VI, lines 346-348). The author concluded that to keep spouses under control is not possible because guardians can be bribed. For similar considerations a finite succession of guardians of guards does not seem to be a solution. So, Juvenal suggests that the problem to guard the guards has no solution, i.e., there is not way to control the guardians. In conclusion, until now, we have two different absolute answers to the same question. One of them optimistic given by Plato, another one pessimistic, there is no way to control the controllers.

The aim of this article is to give a partial answer to this question without recourse to an endless succession guard of guards. We argue that an infinite cycle of guardians is not necessary to control the government. When citizens are voters in a democratic country two levels of guards are enough, under the assumption that it will be possible for the citizens to vote for a new government with the expectation that this government will be cost efficient in controlling corruption and will practice appropriate fines against corrupts. In our work we have officials, the individuals that must be controlled, the government or the ruler elite, is the first level of guards, and the second level is made up of citizens. We conclude that we cannot be as pessimistic as Juvenal or as optimistic as Plato.

Nevertheless, this possibility to stop corruption by means of citizen participation in an electoral process is open only in democratic countries where elections exist. Under dictatorial governments this participation is much more complicated and takes much more tortuous forms. Situations that we do not consider in this work. In spite of the natural limitations of our model, it allows as to describe the evolution of a corruption in a society and to know its causes and possible restraints for increasing processes of corruption. In this sense, our model allows a deeper insight in the acknowledgement of the future development of the current conditions, i.e., from the mathematical point of view, the initial conditions of the system. We focus mainly on consequences and insights that may be 
derived from this approach. We postpone an empirical analysis and testing of the model to a subsequent publication.

We do not give an exact definition of corruption. ${ }^{1}$ Moreover, we consider only one of its forms of expression, the abuse of the officials, more interested in their own profits, rather than fulfilling their duties. We will show that the persistence of this behavior in a democratic country depends on the degree of intolerance of citizens with respect to this behavior. More precisely, we introduce a game with three players (populations): government, officials, and citizens where the first two players must choose between a corrupt or honest behavior. Citizens have a political role influencing the prospective of a corrupt or non-corrupt government being maintained in power. This political influence results in a quantity that we call the index of intolerance to corruption. The persistence of corrupt behavior in a democratic country depends on the degree of intolerance of citizens. Such index will be function of the percentage of corrupt officials existing in each time. The main characteristic of this index is that it has a direct influence on the probabilities that the current government will be re-elected. To do this we consider that the index is continuous with respect to time, and so, locally it does not change too much. We want to consider different versions of this index, for instance depending on citizens perception of corruption by the media and other characteristics in future works.

We consider an evolutionary version of the game by means of the replicator dynamics. More precisely, we obtain five steady states for the dynamics: four of them are pure equilibria where in both the government and officials population only one strategy is chosen: either corrupt or noncorrupt. The other equilibrium corresponds to a mixed strategy where the two players chose to be corrupt or not with a certain probability, or equivalently, to a certain ratio of between the two strategies within each population. We do the stability analysis of the stationary points of the system according to the index of intolerance to corruption and other relevant quantities of the model. We analyze and fully characterize the possible trajectories of the system. In particular, we show how a sudden change in the evolution of corruption might occur as a consequence of changes in the intolerance index. The trajectories of the system are initial condition dependent and we characterize the evolutionary outcomes of the system, i.e., the corruption behavior patterns that are selected by means of an evolutionary selection dynamics such as the replicator dynamics.

The rest of the work is organized as follows: in the next section we introduce a formal model of a process involving one government and officials. To analyze the evolution of corruption we consider a particular normal form game where the players are the government and officials, where citizens have an influence through a dichotomous variable that represents the externality of the government in case of re-election. In Section 3 we consider the corruption as a self-reinforcing mechanism. In Section 4 we introduce the Index of Intolerance to Corruption. This index is an important quantity in our model, and it can help explain, as well as other quantities, the process of reversing of corruption. In this work the index of intolerance to corruption represents an externality to governments, expressed through popular participation in an election. In Section 5 we consider a dynamical system given by the replicator dynamics to explain the evolution of the corruption in a society. In Section 6 we analyze the relationships between dynamical equilibria, Nash equilibria, and stability, studying these relations according to characteristics of government and officials in the game. Even when we consider the intolerance index as determined by the utilities of the citizens, and this utility depends negatively on the officials' corruption, in this section we consider this index as given. Note that the analysis of the stability is only valid in a neighborhood of an equilibrium. Thus by continuity, we can considerer that in these neighborhoods the intolerance index does not change too much. Supported in this claim we consider the index as a constant in each one of these neighborhoods. In Section 7 we consider some particular cases in which it is possible to accurately describe the evolution of corruption from initial conditions given. In Section 8 we make some considerations about the role of the index of intolerance of corruption and we mention some possible extensions of this index. In the last section we present some conclusions. 


\section{The model}

Consider an economy or society, where the central authority is elected by universal suffrage of citizens. By central authority or national government, we understand the president and his political sector. They make up the ruling elite. The government can be re-elected or not after each electoral period through universal suffrage. The president and members of his political sector, in turn, appoint public officials who may or may not be renewed by the new government. These officials are in charge of carrying out the legal and administrative management of the government and serve directly to the citizens when they require to carry out this type of formalities before the central authority. At the end of each election period, the officials (those who remain in their charges and the new ones) must choose between two different behaviors namely, properly fulfilling its role or, when her participation is required by a citizen, he fulfils his duty as long as the citizen pays for it a certain amount of money.

We call an honest or non-corrupt official the one that chooses to unconditionally fulfill its functions, otherwise we call the official a dishonest or corrupt official. Sometimes, a dishonest official is colluded with a member of the central authority and both take advantage for this behavior. Several examples of this kind of collusion are considered in (Thompson, 1995) and (Lessig, 2011).

In general, corruption can be defined as the misuse of public power for private benefit. For instance, government official collect bribes for providing permits, licenses, passage through costumers, or avoiding the entrance to competitors in a given market. Such behavior may give room to an increase of the dishonest behavior in the whole society.

Following Shleifer and Vishny (1993), we define the governmental corruption as the complicity of the government (the ruling elite) with officials that sell government property for personal gain. We summarize the activity of the government saying that it must choose between to follow a corrupt behavior or a non-corrupt behavior, meaning to act in complicity with corrupt officials, or alternatively, punishing them.

But even when some members of the government can be attracted to acting in collusion with dishonest officials, it is necessary to consider that the government is interested in being re-elected for the next period, and they know that this happens only if citizens are satisfied with the performance of the government. Citizens will judge the performance of the central authority through the work of officials who deal directly with them. Citizens prefer a non-corrupt government, but they do not have complete information about the behavior of the government. They know this information only in an indirect way, and only if they have taking contact with some official. The fact that citizens have incomplete information results in probabilities of re-electing or not the current government, being it corrupt or not. Since government has a certain valuation for being re-elected this mechanism results in an externality for the government caused by election. We will describe below how this externality (related to the index of intolerance to corruption) will appear in the game as well as its main consequences in the following section of this work.

At the end of every electoral period, citizens must choose between to re-elect the government or not. Every citizen prefers a non-corrupt government to a corrupt one; however, they do not have perfect information about the governmental corruption. For a citizen, in our model, corruption means having to pay a corrupt official for a service that would have no cost if done through an honest official. It is consistent then, that they prefer non-corruption to corruption. However, even when citizens prefer a non-corrupt government to a corrupt one, some of them can vote by mistake for the re-election of a corrupt government or vote against the re-election of a non-corrupt one. On the other hand, we assume that a corrupt government can try to corrupt the citizens by means of some kind of payment or royalties in exchange for their vote as we will describe in the game model below ${ }^{2}$.

\footnotetext{
${ }^{2}$ The vote buying consists in the bribery of a group of citizens with the aim of obtaining their vote in favor of the re-election. The voter would be compensated with cash or some bonus. This modus operandi is well documented in literature, see for instance (Grego, 2013) and (Allen \& Allen, 1981).
} 
The model can be formalized as a normal form game. The sets of pure strategies are as follows:

(1) Officials must choose between two pure strategies: to be corrupt or not, respectively symbolized by $O_{c}$ and $O_{n c}$, so that we have $\Gamma_{O}=\left\{O_{c}, O_{n c}\right\}$.

(2) The central authority or government must choose in the set of pure strategies $\Gamma_{G}=\left\{G_{c}, G_{n c}\right\}$. A corrupt policy (meaning to collude with corrupt officials) is symbolized by $G_{c}$ while an honest or non-corrupt policy is denoted by $G_{n c}$. This represents the behavior of the political elites.

(3) We consider that citizens are heterogeneous in preferences. Individual preferences are defined by a utility function $u_{i}:[0,1] \times \Re_{+} \rightarrow \Re_{+}$that we assume to be continuously differentiable, such that $\left(n_{c}, P\right)^{\circ} u_{i}\left(n_{c}, P\right)$ where $n_{c}$ is the relative amount of corrupt officials and $P$ is the payment offered by the government for the vote of the citizen. In addition we consider that $\frac{\partial u_{i}\left(n_{c}, P\right)}{\partial n_{c}}\left\langle 0, \frac{\partial u_{i}\left(n_{c}, P\right)}{\partial P}\right\rangle 0$.

The payoffs for officials and government are represented in the following table. At the end of every period, the ruling elite must choose between to follow a corrupt or a non-corrupt behavior (rows), and officials must choose between a corrupt or non-corrupt behavior (columns). The first payoff is the officials' payoff and the second is the government's payoff.

$$
\begin{array}{ccc}
O \mid G & G_{c} & G_{n c} \\
O_{c} & W+M_{c}-M_{g}, M_{g}-W+V_{G_{c}}-K P & W+M_{c}-M, M-W-e+V_{G_{n c}} \\
O_{n c} & W-M_{g}^{\prime}, M_{g}^{\prime}-W+V_{G_{c}}-K P & W,-W+V_{G_{n c}}
\end{array}
$$

where:

- By $W$ we symbolize the wage of the officials which is paid by the government.

- Mis a fine imposed by an honest government to a dishonest official.

- $M_{c}$ corresponds to the bribe that a dishonest official takes from a citizen when his participation in a certain activity is required.

- $M_{g}$ is the amount that the dishonest official must pay to his partner in the government when a collusion occurs and both officials and government are corrupt. This quantity may be seen as a fraction of the bribe that the corrupt official charges on citizens: $M_{g}=\theta M_{c}$.

- $M_{g}^{\prime}$ is the amount that an honest official must pay to a dishonest government to keep his position or because they do not want to be punished for breaching the rules of coexistence. We note that $M_{g}^{\prime}$ can be negative, i.e., a reward given by the corrupt government to honest officials. When $M_{g}^{\prime}$ is positive, it can also be considered as legal appropriation of the officials' welfare due to ideological reasons.

- eis the cost associated with the capture of a corrupt official. We assume that this cost is a measure of the governmental efficiency in fight against corruption.

- $V_{G_{c}}$ and $V_{G_{n c}}$ are dichotomous random variables taking, respectively, the values $V_{G_{c}}$ and 0 (with probabilities $q_{G_{c}}$ and $1-q_{G_{n c}}$ ), and the values and (with probabilities and). For simplicity, we keep the same notation for the values the variables may take and the variables themselves. These two random variables correspond, respectively, to the value that a corrupt government and a non-corrupt government assign to re-election for the next period.

- By $K P$ we symbolize the total amount of money that the ruler elite offers to the citizens to buy their votes, where $P$ is the unitary value paid to each person and $K$ is the number of citizens to which the government pays is such that $0 \leq K \leq H$ where $H$ is the total number of citizens.

The parameters of the model may be considered as average of what is observed in the whole society. For instance, it may be that an honest government dismisses some corrupt officials instead of 
imposing fines on them. This situation may be interpreted as a fine that equals the wage of the official. Another possibility, for instance, is when a honest official works for an honest government, the government may consider that this has a positive benefit apart from the wage he pays. Thus, the wage parameter will reflect the average of these situations in the whole society. Similarly for the order of magnitude of fines and briberies from the part of the officials that may be different across society, the parameter values representing a societal average. For the sake of simplicity, we consider that the wages are the same whether officials and government are corrupt or not.

It is clear that the members of a corrupt government have an interest in perpetuating themselves in power, either because of their interest in continuing to be enriched or because of their fear of being penalized by a future government. On the other hand, the interest that a non-corrupt government has in being re-elected is based on the will its members to fulfil a function of public interest.

Our analysis basically refers to the evolution of corruption in democratic countries, where citizens have the opportunity to express themselves with relative independence. The case of countries under dictatorial regimes can be considered as an extreme case, in which the probability of government being maintained in power is total, so the government always has the externality values $V_{G_{n c}}$ or $V_{G_{n c}}$. From now on we will focus in a democratic country, where the ruler elite must undergo an electoral process $^{3}$.

\section{The choice of citizens}

As stated above, citizens are not decision makers in the game we considered, but their choice has a political influence in the outcome of the game and on the decisions of government and officials. The ruler elite must undergo an electoral process on which it will seek to influence in various ways.

For instance in case of a corrupt government buying votes. Note that, even in this case, not necessarily all citizens will receive some payment from a corrupt government. The ruling elite chooses who and how much to pay. To simplify we will consider that some citizens will receive an amount equal to $P>0$ monetary units and others receive 0 .

We have that, fixed $p \in\{0, P\}$ each citizen prefers an honest government to a non-corrupt one, i.e.;

$$
\text { if } \bar{n}_{n c}>n_{n c}^{\prime} \text { then } u_{i}\left(\bar{n}_{n c}, p\right)<u_{i}\left(n_{n c}^{\prime}, p\right) \text {, }
$$

where $n_{n c}=1-n_{c}$ is the relative amount of non-corrupt officials. The citizens measure the level of corruption by the percentage of corrupt officials acting in the public administration. This is a natural assumption, because for a citizen, corruption means having to pay for a service that must be provided free of charge.

Let $K$ be the subset of citizens receiving the amount $P$. The subset $K$ and the value of $P$ are fixed by the ruler elite and depend on the estimates that this elite does.

- Not necessarily all citizen will receive some payment made by a corrupt government. The ruling elite chooses who to pay. Some citizens will receive an amount equal to $P>0$ monetary units, and others will receive 0.

- The ruler elite of a corrupt government will offer an amount $P=P\left(n_{c}\right)$ to each citizen in a subgroup $K \subset H$ where $P\left(n_{c}\right)$ is high enough, in the sense that $u_{i}\left(n_{c}, P\right)>u_{i}\left(n_{c}^{\prime}, 0\right)$ for all $i \in K$ and for all $n_{c}^{\prime}<n_{c}$. The value of $P\left(n_{c}\right)$ increases with $n_{c}$. We assume that the utility function $u_{i}\left(n_{c}, P\left(n_{c}\right)\right)$ is decreasing in $n_{c}$. In other words, the amount $P$ is enough to convince the citizen to vote when the number of corrupt officials is higher since it yields a higher utility than lower

${ }^{3}$ It should be noted that in most circumstances, a dictatorial regime also has elections that are fraudulent (for example, pre-1974 Portugal). Thus, our model may also explain these situations. 
corruption without any payment, but still, in this situation, the citizen places greater importance in the amount of corrupt officials, and this is why $u_{i}\left(n_{c}, P\left(n_{c}\right)\right)$ is decreasing.

- Let $\bar{P}$ be the maximum amount that a corrupt government can offer to citizens in exchange for their votes. Note that for all we have that and for all $i \in K$ we have that $u_{i}(1,0) \leq$ $u_{i}\left(n_{c}, P\left(n_{c}\right)\right) \leq u_{i}(0, \bar{P})$ and for all $i \notin K$ we have that $u_{i}(1,0) \leq u_{i}\left(n_{c}, 0\right) \leq u_{i}(0,0)$.

The choice of citizens is randomized because the information they have is not complete. We consider that the probability of re-electing the government or not depends directly on their relationship with the officials, and this probability decreases as the number of corrupt officers increases, so that this may be distorted by personal experience. In this case, even high values of $P$, will not give the result sought by the ruling elite and the citizens will vote for not re-electing a corrupt government.

Definition 1 We shall symbolize by $Q_{G_{c}}=\left(q_{G_{c}}, q_{N G_{c}}\right)$ and by $Q_{G_{n c}}=\left(q_{G_{n c}}, q_{N G_{n c}}\right)$ the distributions of probabilities that a corrupt government, (respectively a non-corrupt one) be re-elected. These probabilities can be considered as two different mixed strategies of the citizens.

Let us introduce the following boundary values:

$$
\begin{aligned}
& m_{K}=\min _{i \in K} u_{i}(1,0) \text { and } M_{K}=\max _{i \in K} u_{i}(0, \bar{P}) \\
& m_{n K}=\min _{i \notin K} u_{i}(1,0) \text { and } M_{n K}=\max _{i \notin K} u_{i}(0,0) .
\end{aligned}
$$

We consider that the probability that a citizen votes for the re-election of a government is proportional to the utility function. Then, for a fixed $n_{c}$ and $P\left(n_{c}\right)$ it follows that:

- The probability that a citizen votes for the re-election of a corrupt government is given by:

$$
\begin{aligned}
& \frac{m_{K}}{M_{K}} \leq q_{G_{c}}^{i}=\frac{\alpha_{i}}{M_{K}} u_{i}\left(n_{c}, P\left(n_{c}\right)\right), \forall i \in K \text { and } \\
& \frac{m_{n K}}{M_{n K}} \leq q_{G_{c}}^{i}=\frac{\alpha_{i}}{M_{n K}} u_{i}\left(n_{c}, 0\right), \forall i \notin K
\end{aligned}
$$

- The probability that a citizen votes for the re-election of a non-corrupt government is given by:

$$
\begin{aligned}
\frac{m}{M} \leq q_{G_{n K}}^{i} & =\frac{\alpha_{i}}{M} u_{i}\left(n_{c}, 0\right) \\
\text { where } m & =\min _{i \in H} u_{i}(1,0), M=\max _{i \in H} u_{i}(0,0) .
\end{aligned}
$$

And so

$$
\begin{aligned}
& q_{G_{c}}=\prod_{i \in H} q_{G_{c}}^{i}=\Pi_{i \in K} \frac{\alpha_{i}}{M_{K}} u_{i}\left(n_{c}, P\left(n_{c}\right)\right) \Pi_{i \notin K} \frac{\alpha_{i}}{M_{K}} u_{i}\left(n_{c}, 0\right) \\
& q_{G_{n c}}=\Pi_{i \in H} q_{G_{n c}}^{i}=\Pi_{i \in H} \frac{\alpha_{i}}{M} u_{i}\left(n_{c}, 0\right) .
\end{aligned}
$$

Remark 1 We observe that the probability of the current government being re-elected depends on the perception of the citizens about the officials' corruption. The probabilities decrease with the percentage of corrupt officials. 


\section{Corruption as a self-reinforcing mechanism}

The von Neumann-Morgenstern utility theorem shows that, under certain axioms of rational behavior, a decision-maker faced with risky outcomes of different choices will behave as if he is maximizing the expected values of some function (the von Neumann-Morgenstern utility function) defined over the potential outcomes at some specified point in the future. We will follow this point of view to describe the behavior of the agents involved in our model. We assume that the values of the utility function associated with each choice (for the ruling elite and for officials) are the potential profits in each state of the world.

Let $N_{c}(t)$ be the quantity of corrupt officials in time $t, N_{n c}(t)$ the quantity of honest officials in time $t$, and $N=N_{c}+N_{n c}$. $N$ is fixed, but the distribution of officials can change along time.

Taking in consideration that $q_{G_{c}}$ and $q_{G_{n c}}$ are respectively, the probabilities that a corrupt and a non-corrupt government get re-elected, we obtain that the expected payoff of a dishonest government corresponds to

$$
E\left(G_{c}\right)(t)=N_{c}(t) M_{g}+N_{n c}(t) M_{g}^{\prime}-N W+R_{G_{c}}-K P,
$$

and the total payoff of a honest government corresponds to

$$
E\left(G_{n c}\right)(t)=-N W+(M-e) N_{c}(t)+R_{G_{n c}},
$$

where $R_{G_{c}}$ and $R_{G_{n c}}$ are the expected values of governments in case of being maintained in power, i.e., $R_{G_{c}}=V_{G_{c}} q_{G_{c}}$ and analogously for a non-corrupt government $R_{G_{n c}}=V_{G_{n c}} q_{G_{n c}}$.

We will also use the notation $n_{c}(t)=\frac{N_{c}(t)}{N}$, the share of corrupt officials in time $t$ and $n_{n c}(t)=$ $\frac{N_{n c}(t)}{N}$ the share of non-corrupt (honest) officials in time $t$. We have that $n_{c}(t)+n_{n c}(t)=1$ for all time $t$.

We denote by $P\left(G_{c}\right)$ the probability that the government follows a corrupt policy. We shall see later that in our model this probability is determined endogenously. Note that $P\left(G_{n c}\right)=1-P\left(G_{c}\right)$ is the probability that the government follows a non-corrupt policy. The expected profit of a dishonest official is given by

$$
E\left(O_{c}\right)=\left(W+M_{c}-M_{g}\right) P\left(G_{c}\right)+\left(W+M_{c}-M\right) P\left(G_{n c}\right) .
$$

The expected profit of an honest official is given by

$$
E\left(O_{n c}\right)=\left(W-M_{g}^{\prime}\right) P\left(G_{c}\right)+W P\left(G_{n c}\right) .
$$

Given that we assume a rational behavior of the different agents involved, it follows that, the quantity of dishonest official increases if and only if $E\left(O_{c}\right)>E\left(O_{n c}\right)$ i.e., if and only if:

$$
\left(W+M_{c}-M_{g}\right) P\left(G_{c}\right)+\left(W+M_{c}-M\right)\left(1-P\left(G_{c}\right)\right)>\left(W-M_{g}^{\prime}\right) P\left(G_{c}\right)+W P\left(G_{n c}\right) .
$$

After some algebra we obtain the following statements: $E\left(O_{c}\right)>E\left(O_{n c}\right)$ if and only if:

$$
P\left(G_{c}\right)>\frac{M-M_{c}}{M-M_{g}+M_{g}^{\prime}}
$$

and $E\left(G_{c}\right)>E\left(G_{n c}\right)$ if and only if

$$
n_{c}>\frac{\left(R_{G_{n c}}-R_{G_{c}}\right)-N M_{g}^{\prime}+K P}{N\left(M_{g}-M_{g}^{\prime}-M+e\right)} .
$$

The next proposition summarizes these facts

Proposition 1 Officials prefer to choose a dishonest behavior if and only if the government corruption is large enough, and reciprocally a high number of corrupt officials encourage governmental corruption. 
Remark 2 Note that if the fines are relatively low with respect to what a corrupt official can obtain by an illegal payment for his services, i.e., if $\frac{M_{c}}{M} \geq 1$ even when the government prefers to follow an noncorrupt behavior $\left(M_{g}=0\right)$ it is more profitable for the officials to follow a corrupt conduct. So, along the time, the amount of corrupt officials increases, and consequently, after some time the government become corrupt. More precisely, this will change in the governmental behavior, will happen as soon as the inequality (9) is verified.

A general conclusion can be obtained from proposition (1) and summarized in the following way: corruption corrupts. More explicitly, this proposition says that corruption is a self-reinforcing mechanism. The question now is how to break down this process. The answer is in the degree of intolerance of citizens to corruption. It should be considered that even when some elements of the ruling class are willing to follow a corrupt behavior, if this attitude favors an increase in the number of corrupt officials, their government may not be re-elected, and in that case they do not obtain the value of the re-election externality $V_{G_{c}}$. This possibility depends on the interplay between the variables of the model. One particular quantity is the index of intolerance of corruption that we now introduce.

\section{The index of intolerance to corruption}

The intolerance of citizens toward corrupt acts plays a fundamental role regarding the evolution of corruption in society. The possible expressions of this intolerance can take different forms under different regimes. Under dictatorships their manifestations must take on very creative and sometimes dangerous forms. In general, in democratic countries, it manifests itself through the citizen's vote, although it may also acquire other forms. In our analysis we will refer to the expression of this intolerance in the form of citizens voting in an electoral process in democratic countries.

Under this framework, now we define the index of intolerance to corruption as follows:

Definition 2 (The Index of Intolerance to Corruption) Let $q_{G_{n c}}$ be the probability that a corrupt government is re-elected given that the percentage of corrupt officials $n_{c}$ is and let $q_{G_{c}}$ be the probability that a non-corrupt government is re-elected. We define the index of intolerance to corruption by the difference:

$$
D_{i t}=q_{G_{n c}}-q_{G_{c}} .
$$

This index captures the social sensibility to the corruption. Note that $-1 \leq D_{i t} \leq 1$ and

$$
\begin{aligned}
& R_{G_{n c}}-R_{G_{c}}=V_{G_{n c}} q_{G_{n c}}-V_{G_{c}} q_{G_{c}}= \\
& =\left(V_{G_{n c}}-V_{G_{c}}\right) q_{G_{n c}}-V_{G_{c}}\left(q_{G_{c}}-q_{G_{n c}}\right)= \\
& =\left(V_{G_{n c}}-V_{G_{c}}\right) q_{G_{n c}}+V_{G_{c}} D_{i t} .
\end{aligned}
$$

This expression shows that the difference between the expected value of a non-corrupt government being re-elected and the one that corresponds to a non-corrupt government being re-elected grows with the index of intolerance to corruption.

Because corruption is willfully hidden, it is not easy to measure it directly (Seligson, 2002). There have been many attempts to solve this problem but they have all came up with limitations, see for instance (Campbell, 2013) and (Mauro, 1995). We interpret the degree of corruption of government as varying according to the services that officials provide, i.e., depending on the number of corrupt 
officials. Consequently, the indignation that corrupt services cause among citizens can help to stop corruption.

Note that, under the usual assumptions relative to utilities, the marginal rate of substitutions of corruption for money $M R S_{N_{c} P}$ i.e., the amount of money that a citizen hopes to receive to accept a higher level of corruption, without changing his level of utility, is given (locally) by the expression:

$$
\operatorname{MRS}_{n_{c}, P}=\frac{\partial P}{\partial n_{c}}=-\frac{\partial u_{i} / \partial n_{c}}{\partial u_{i} / \partial P}>0
$$

Therefore, if the disutility of an increase in corruption for the $i-t$ th citizen is very high, i.e., the numerator in (12) is very low (recall that $\partial u_{i} / \partial n_{c}<0$ for all $i \in\{1, \ldots, H\}$ ) then, the corrupt government must pay a very high price to buy his vote. This could have as a result the impossibility of buying the vote of such citizen, decreasing in this way the probability that the citizen votes for the corrupt government. Analogously for those citizens for whom the marginal utility of money is lower, i.e., the denominator in (12) is lower, yielding a high marginal rate of substitution. These citizens are also less likely to vote for a corrupt government. In conclusion, we obtain that $\frac{\partial}{\partial n_{c}}\left(q_{G_{n c}}-q_{G_{c}}\right)>0$, i.e., the derivative of the intolerance index with respect to the percentage of corrupt officials is positive. This means that because of the payments that a corrupt government makes, citizens have an indirect perception of the government corruption, resulting in the probability $q_{G_{c}}$ decreasing more rapidly than $q_{G_{n c}}$.

Recall that the marginal rate of substitution is a (local) measure, which may change according to the values of $P$ and $n_{c}$. On the other hand, it should be remembered that the marginal utility with respect to an additional monetary unit is not the same for all citizens and depends, among other things, in the level of their incomes.

Substituting Eq. (11) in the inequality (9) it follows that government prefers the corrupt strategy if and only if

$$
n_{c}>\frac{\left[\left(V_{G_{n c}}-V_{G_{c}}\right) q_{G_{n c}}+V_{G_{c}} D_{i t}\right]-N M_{g}^{\prime}+K P}{N\left(M_{g}-M_{g}^{\prime}-M+e\right)} .
$$

If we consider the additional hypothesis that the externality that a political group in power can obtain in case of being re-elected are the same whether it is corrupt or not, i.e., $V_{G_{c}}=V_{G_{n}}$, then Eq. (13) simplifies and the role of the index of intolerance is very clear:

$$
n_{c}>\frac{V_{G_{c}} D_{i t}-N M_{g}^{\prime}+K P}{N\left(M_{g}-M_{g}^{\prime}-M+e\right)} .
$$

The next corollary holds.

Corollary 1 If citizens are sufficiently intolerant with the bad services provided by corrupt officials, then, according to (13) or (14), it becomes more unlikely that there are enough corrupt officials so that governments prefer to be corrupt, so that the government loses incentives to tolerate or to allow corruption. Insofar as that the degree of tolerance of citizens for the services of corrupt officials decreases or, equivalently, insofar the degree of intolerance for corrupt services increases, the government prefers to punish corrupt officials.

However, note that the strategy "to be corrupt" can be a dominant strategy for the government if its efficiency to capture corrupt officials is low, or equivalently the cost to catch the corrupt officials is high, i.e., if $e>M-M_{g}{ }^{4}$ The cost to catch the corrupt officials is higher in those countries where

\footnotetext{
${ }^{4}$ We assume that costs associated with the capture of a corrupt official are funded by sanctions that a non-corrupt government obtains from fines to corrupt officials. Certainly if this cost exceeds the total amount of fines collected, the government will have to appeal to other sources to perform this task. This point is not considered in this work.
} 
the effectiveness of the legal system is low, and in this case, and also when the intolerance index is low, we may be in presence of a negative cycle where an inefficient legal system becomes a cause and a consequence of corruption. We will analyze how exogenous changes in these and other quantities can change the processes of evolution of corruption and revert the spreading of corruption.

Let us analyze the social evolution of corruption by means of the replicator dynamics.

\section{The evolution of corruption}

To explain the social evolution of corruption, we shall follow an evolutionary approach. This approach is based on the fact that strategies that make a person do better than others will be retained, while strategies that lead to failure will be abandoned. The success of a strategy is measured by its relative frequency in the population at any given time. Strategies change over time as a function of their relative success in an environment that is made up of other players that keep changing their own strategies adaptively.

Initially people decide their strategies independently. We assume that individuals in every time try to improve his welfare and that they follows a myopic behavior, because officials and government cannot forecast the consequences of the changes in the relative frequency of their strategies can provoke. In addition, we consider that officials do not know with absolute accuracy the likelihood that the government act corruptly, neither the government knows exactly the percentage of corrupt officials.

Periodically, they compare the obtained returns and after some time, some of them update their strategic choices, switching for the, apparently, most profitable strategies. So, in each period, the percentage of individuals that follows a given strategy increases if the expected payoff of such strategy is greater than the average payoff obtained by the population. Otherwise, if the expected payoff is performing worse than the average, that strategy becomes less frequent in the population. The dynamical system summarizing these facts is the replicator dynamics (see (Weibull, 1995)). In other words, the replicator dynamics consider that the difference between the expected payoff of a strategy and the average payoff of all strategies is the per-capita change in the frequency of the strategy in the population. Along time, more profitable strategies become the most widely used. In addition we consider that, depending on the prevailing social conditions in each period, the strategy that offers the best return can change.

Let $N_{c}(t)+N_{n c}(t)=N$, be the total amount of officials. $N_{c}(t)$ is the number of corrupt official in time $t$ and $N_{n c}(t)$ the amount of not corrupt officials in time $t$. The amount of officials following one or another strategy may change, but, we assume that the total amount of officials is constant and equal to $N$.

We denote by $n_{i}(t)=\frac{N_{i}(t)}{N}$ the percentage of corrupt officials following the strategy $i \in\left\{O_{c}, O_{n c}\right\}$. By $n(t)=\left(n_{c}(t), n_{n c}(t)\right)$ we symbolize the distribution of the officials over the set of pure strategies, in each time $t$, by $g(t)=\left(g_{c}(t), g_{n c}(t)\right)$ the mixed strategy of the government in time $t$.

According with the replicator dynamics discussed above, the growth rate of corrupt officials is given by the following differential equation:

$$
\dot{n}_{c}=n_{c}\left[E\left(O_{c} \mid g\right)-\bar{E}\right]
$$

where $\bar{E}=n_{c} E\left(O_{c} \mid g\right)+n_{n c} E\left(O_{n c} \mid g\right)$ is the expected payoff of the officials when they follow a corrupt strategy, and $E\left(O_{c} \mid g, n\right)$ and $E\left(O_{n c} \mid g, n\right)$ denote, respectively, the expected value of a corrupt behavior and a non-corrupt behavior by an official, given a distribution $g$ over the government behavior. Analogously for the percentage of individuals following the honest behavior, $n_{n c}(t)=$ $1-n_{c}(t)$, for all $t$. After some algebra we obtain the equivalent dynamical system:

$$
\begin{aligned}
& \dot{n}_{c}=n_{c}\left(1-n_{c}\right)\left(E\left(O_{c} \mid g\right)-E\left(O_{n c} \mid g\right)\right), \\
& \dot{n}_{n c}=-\dot{n}_{c} .
\end{aligned}
$$


By $\dot{n}_{i}$ we represent the derivative with respect to the time of the percentage of official following the strategy $i$. All these variables are time depending, but to simplify we do not write the variable $t$.

To measure the evolution of the governmental corruption we introduce $g_{c}$ as an index measuring the percentage of corrupt acts committed in public offices regarding the total of acts performed in these government agencies. ${ }^{5}$ We endogenize the probability of a government being corrupt by considering the index $g_{c}$ that represents the percentage of corrupt acts made by a government on the total acts of government performed as the probability that government follows a corrupt strategy. In other words, this will be the mixed strategy of the government over his set of pure strategies. Then, in a similar way, we obtain that the evolution of the government policy can be represented by the following dynamical system.

$$
\begin{aligned}
& \dot{g}_{c}=g_{c}\left(1-g_{c}\right)\left(E\left(G_{c} \mid n, D_{i t}\right)-E\left(G_{n c} \mid n, D_{i t}\right)\right), \\
& \dot{g}_{n c}=-\dot{g}_{c} .
\end{aligned}
$$

where $\dot{g}_{i}$ represents the derivative with respect to time of the probability $g_{i}(t)$ that the government follows strategy i. $E\left(G_{c} \mid n, D_{i t}\right)$ and $E\left(G_{n c} \mid n, D_{i t}\right)$ represent, respectively, the expected value of a corrupt behavior and a non-corrupt behavior by the government, given a distribution $n$ of the officials over their available strategies and the degree of intolerance to corruption $D_{i t}$.

This dynamical system with four equations can be summarized in the following system with only two differential equations:

$$
\begin{aligned}
& \dot{n}_{c}=n_{c}\left(1-n_{c}\right)\left(E\left(O_{c} \mid g\right)-E\left(O_{n c} \mid g\right)\right), \\
& \dot{g}_{c}=g_{c}\left(1-g_{c}\right)\left(E\left(G_{c} \mid n, D_{i t}\right)-E\left(G_{n c} \mid n, D_{i t}\right)\right) .
\end{aligned}
$$

Using equalities (3), (4), (5) and (6), after some algebra we obtain:

$$
\begin{aligned}
& \dot{n}_{c}=n_{c}\left(1-n_{c}\right)\left[\left(M_{c}-M_{g}-M_{c}+M+M_{g}^{\prime}\right) g_{c}+M_{c}-M\right] \\
& \dot{g}_{c}=g_{c}\left(1-g_{c}\right)\left[n_{c} N\left(M_{g}-M_{g}^{\prime}-M+e\right)+N M_{g}^{\prime}+R_{G_{c}}-R_{G_{n c}}-K P\right]
\end{aligned}
$$

To simplify the writing we can consider

$$
\begin{array}{ll}
A=-M_{g}+M+M_{g}^{\prime}, & B=M_{c}-M \\
A^{\prime}=N\left(M_{g}-M_{g}^{\prime}-M+e\right), & B^{\prime}=N M_{g}^{\prime}+R_{G_{c}}-R_{G_{n c}}-K P
\end{array}
$$

then the dynamical system (18) takes the form:

$$
\begin{aligned}
& \dot{n}_{c}=n_{c}\left(1-n_{c}\right)\left(A g_{c}+B\right) \\
& \dot{g}_{c}=g_{c}\left(1-g_{c}\right)\left(A^{\prime} n_{c}+B^{\prime}\right) .
\end{aligned}
$$

\section{Dynamic equilibria, Nash equilibria, and stability}

In this section we analyze the equilibria of the dynamical system given by Eq. (20) and analyze their stability. The stability analysis is a local property, i.e., it is valid only in a neighborhood of each

\footnotetext{
${ }^{5}$ Most indexes measuring corruption actually measure proxies for corruption because corruption is a difficult phenomenon to measure. An example of such an empirical index of the perceived governmental corruption is Transparent International's (TI) Corruption Perceptions Index (CPI). This index captures information about administrative and political aspects of corruption. However, its use has not come without criticism (see (Campbell, 2013)).
} 
equilibrium point. In this neighborhood we consider as given the values of the parameters of the model and also the value of the intolerance index. In small neighborhood of the equilibrium they can be considered as constant. Note that in the dynamical system (20) the index of intolerance affects only the differential equation of the government. It is possible to consider that the ruler elite has not exact knowledge of this index and consider it as a mean value on that neighborhood. With this study, we characterize the long-term evolution of corruption.

\section{Government and officials characteristics}

To analyze the stability of the equilibria, we will use the following characterizations of corrupt and non-corrupt governments.

- The non-corrupt government practices appropriate fines if, (), and it practices inadequate fines if $M>M_{c},(B<0)$, and it practices inadequate fines if $M<M_{c},(B>0)$.

- Let the non-corrupt government re-election threshold be

$$
T_{1}=N M_{g}^{\prime}-K P+R_{G_{c}}
$$

The non-corrupt government has high re-election power if $V_{G_{n c}} q_{G_{n c}}>T_{1},\left(B^{\prime}<0\right)$, and it has low re-election power if $V_{G_{n c}} q_{G_{n c}}\left\langle T_{1},\left(B^{\prime}\right\rangle 0\right)$.

- Let the non-corrupt government efficiency threshold be

$$
T_{2}=R_{G_{n c}}-R_{G_{c}}+\left(M-M_{g}\right)+K P .
$$

The non-corrupt government is cost efficient in fighting against corruption if $e<T_{2} / N,\left(A^{\prime}+\right.$ $\left.B^{\prime}<0\right)$ and it is cost inefficient in fighting against corruption if $e>T_{2} / N,\left(A^{\prime}+B^{\prime}>0\right)$.

- The corrupt government penalizes more honest officials than dishonest officials if $M_{g}^{\prime}>M_{g}-M_{c},(A+B>0)$, and penalizes more dishonest officials than honest officials if $M_{g}^{\prime}<M_{g}-M_{c},(A+B<0)$.

Remark 3 We see that the non-corrupt government threshold increases with the expected value $R_{G_{c}}$ of the externality associated with a corrupt government being maintained in power. In other words, it is less likely that a non-corrupt government has high re-election power when the expected value of the externality for a corrupt government increases. Similarly, the threshold decreases when the total amount KP paid by a government in buying votes increases. Thus, it is more likely that a non-corrupt government has high re-election power. We may see this as a negative popularity effect on the government, yielding a higher re-election power to a non-corrupt government.

\section{Remark 4}

It is possible to consider the case $M_{g}^{\prime}<M_{g}-M_{c}$. If we interpret $M_{g}$ as a fraction $\theta$ of $M_{c}$, then $A+B$ is indeed positive. However, it could happen that this quantity is negative if a corrupt government is charging corrupt officials $\left(M_{g}\right)$ more than the bribe that the corrupt officials receive $\left(M_{c}\right)$, i.e., $\theta>1$, meaning that the government takes the full bribe, plus some amount from the salary of the official, or equivalently, that officials are paying government a portion of their salaries to keep their jobs. Another possible interpretation is that the amount $M_{g}^{\prime}$ is negative meaning that an honest official receives money from a dishonest government to keep his position. This kind of corruption of the ruling elites can be considered like a legal corruption associated to self-imposed laws charging 
severe fines to officials that are corrupt by breaking these laws and so breaking the (ideological) solidarity with the government. We shall see that this condition may lead to the equilibrium corresponding to a corrupt government with honest officials being stable.

\section{Nash equilibria and steady-states}

The dynamical system (20) has the following four dynamic equilibria corresponding to pure strategies of the game. Depending on the value of parameters, these points may or may not correspond to Nash equilibria for the sub-game played by officials and government. In this framework, there are four possible equilibria in pure strategies and one in mixed strategies.

1. The corruption equilibrium $\left(n_{c}^{1}, g_{c}^{1}\right)=(1,1)$ is a Nash Equilibrium if and only if

$$
E\left(O_{c}\right) \geq E\left(O_{n c}\right) \text { and } E\left(G_{c}\right) \geq E\left(G_{n c}\right)
$$

This equilibrium is in correspondence with a situation of a chaotic country where the law is not respected and general levels of corruption are high.

2. The corrupt officials equilibrium $\left(n_{c}^{2}, g_{c}^{2}\right)=(1,0)$ is a Nash equilibrium if and only if

$$
E\left(O_{c}\right) \geq E\left(O_{n c}\right) \text { and } E\left(G_{c}\right) \leq E\left(G_{n c}\right)
$$

The interpretation of this equilibrium is the case of a de facto government of the officials. It corresponds to the case of a weak de jure government that is unable to control the corruption of the officials and that it is maintained in power by them only to masque corruption.

3. The corrupt government equilibrium $\left(n_{c}^{3}, g_{c}^{3}\right)=(0,1)$ that it is a Nash Equilibrium if and only if

$$
E\left(O_{c}\right) \leq E\left(O_{n c}\right) \text { and } E\left(G_{c}\right) \geq E\left(G_{n c}\right)
$$

The interpretation for this equilibrium is the case of a strong ideological dictatorship that in fact does not allow (illegal) corruption. In other words, where government corruption (that is, corruption by a usually small political elite) may be seen as legal forms of corruption. However, the government imposes its power by force with high penalties for its officials that deviate from honest behavior.

4. The non-corruption equilibrium $\left(n_{c}^{1}, g_{c}^{1}\right)=(0,0)$ is a Nash Equilibrium if and only if

$$
E\left(O_{c}\right) \leq E\left(O_{n c}\right) \text { and } E\left(G_{c}\right) \leq E\left(G_{n c}\right)
$$

It corresponds to the case in which government and officials fulfil their functions and general levels of corruption are low.

On the other hand, the dynamical system (17) has an interior dynamic equilibrium that it is a mixed Nash equilibrium. If $A$ and $A^{\prime}$ are not equal to zero, then the point $\left(n_{c}^{T}, g_{c}^{T}\right)$ is a steady state, where.

$$
\bar{n}_{c}^{T}=-\frac{B^{\prime}}{A^{\prime}}=\frac{\left(R_{G_{n c}}-R_{G_{c}}\right)-N M_{g}^{\prime}+K P}{N\left(M_{g}-M_{g}^{\prime}-M+e\right)} \quad \text { and } \quad \bar{g}_{c}^{T}=-\frac{B}{A}=\frac{M-M_{c}}{M-M_{g}+M_{g}^{\prime}} .
$$

Note that, in our framework, this equilibrium makes sense if 


$$
0 \leq \bar{n}_{c}^{T}=\frac{\left(R_{G_{n c}}-R_{G_{c}}\right)-N M_{g}^{\prime}+K P}{N\left(M_{g}-M_{g}^{\prime}-M+e\right)} \leq 1 \quad \text { and } 0 \leq \bar{g}_{c}^{T}=\frac{M-M_{c}}{M-M_{g}+M_{g}^{\prime}} \leq 1
$$

are satisfied. The steady state $\left(\bar{n}_{c}^{T}, \bar{g}_{c}^{T}\right)$ is a mixed Nash equilibria for the game, i.e., $E\left(O_{c}\right)=E\left(O_{n c}\right)$ and $E\left(G_{c}\right)=E\left(G_{n c}\right)$. We note that if $\bar{n}_{c}^{T}$ is equal to 0 or 1 , then $\left(\bar{n}_{c}^{T}, g_{c}\right)$ is a steady state for any $g_{c}$; and if $\bar{g}_{c}^{T}$ is equal to 0 or 1 , then $\left(n_{c}, \bar{g}_{c}^{T}\right)$ is a steady state for any $n_{c}$.

\section{Stability of equilibria}

In this subsection we see how the stability of the steady-states mentioned above depends on the thresholds characterizing government and officials.

The Hartman-Grobman theorem states that the orbit structure of a dynamical system in a neighborhood of a hyperbolic equilibrium point is topologically equivalent to the orbit structure of the linearized dynamical system.

Assuming that $A$ and $A^{\prime}$ are non-zero, then the point $\left(n_{c}^{T}, g_{c}^{T}\right)=\left(B^{\prime} / A^{\prime},-B / A\right)$ is a steady state for the dynamical system. The linearization at this point is given by the matrix:

$$
J\left(-\frac{B^{\prime}}{A^{\prime}},-\frac{B}{A}\right)=\left[\begin{array}{cc}
0 & -\frac{A^{\prime} B}{A^{2}}(B+A) \\
-\frac{A B^{\prime}}{A^{\prime 2}}\left(B^{\prime}+A^{\prime}\right) & 0
\end{array}\right] .
$$

The eigenvalues of this matrix are:

$$
\lambda= \pm \sqrt{\frac{B^{\prime} B}{A A^{\prime}}\left(B^{\prime}+A^{\prime}\right)(B+A)} .
$$

Thus, if $\frac{B^{\prime} B}{A A^{\prime}}\left(B^{\prime}+A^{\prime}\right)(B+A)>0$ then this point is a saddle point for the dynamics. In other cases the Hartman-Grobman theorem is not conclusive, because the matrix $J$ has eigenvalues with zero real parts, meaning that the point is not hyperbolic.

The corruption equilibrium $\left(n_{c}^{B}, g_{c}^{B}\right)=(1,1)$ corresponding to a fully corrupt society where all officials are corrupt and government always acts in a corrupt way. The matrix corresponding to the linearization is:

$$
J(1,1)=\left[\begin{array}{cc}
-(A+B) & 0 \\
0 & -\left(A^{\prime}+B^{\prime}\right)
\end{array}\right]
$$

The eigenvalues are $\lambda_{1}=-(A+B)$ and $\lambda_{2}=-\left(A^{\prime}+B^{\prime}\right)$. Hence, the corruption equilibrium $\left(n_{c}^{B}, g_{c}^{B}\right)=(1,1)$ is stable if the non-corrupt government is cost inefficient in fighting against corruption and the corrupt government penalizes more honest officials than dishonest officials.

The officials corrupt equilibrium $\left(n_{c}^{2}, g_{c}^{2}\right)=(1,0)$ corresponds to a situation where all officials are corrupt but the government always acts in an honest way. The linearization is

$$
J(1,0)=\left[\begin{array}{cc}
-B & A^{\prime} \\
0 & A^{\prime}+B^{\prime}
\end{array}\right]
$$

The eigenvalues are $\lambda_{1}=-B$ and $\lambda_{2}=\left(A^{\prime}+B^{\prime}\right)$. Hence, the officials corrupt equilibrium $\left(n_{c}^{2}, g_{c}^{2}\right)=(1,0)$ is stable if the non-corrupt government is cost efficient in fighting against corruption but practices inadequate fines.

The government corrupt equilibrium $\left(n_{c}^{3}, g_{c}^{3}\right)=(0,1)$ corresponds to a situation where the government acts in a corrupt way, but officials are forced to be honest. The linearization is

$$
J(0,1)=\left[\begin{array}{cc}
A+B & A^{\prime} \\
0 & -B^{\prime}
\end{array}\right] .
$$


The eigenvalues are $\lambda_{1}=(A+B)$ and $\lambda_{2}=-B^{\prime}$. Hence, the government corrupt equilibrium $\left(n_{c}^{3}, g_{c}^{3}\right)=(0,1)$ is stable if the corrupt government penalizes more honest officials than dishonest officials and the non-corrupt government has low re-election power.

The non-corruption equilibrium $\left(n_{c}^{4}, g_{c}^{4}\right)=(0,0)$ corresponds to a situation where there is a strictly well ruled country; we obtain the linearization:

$$
J(0,0)=\left[\begin{array}{cc}
B & 0 \\
0 & B^{\prime}
\end{array}\right] .
$$

This matrix has two real eigenvalues $\lambda_{1}=B$ and $\lambda_{2}=B^{\prime}$ and then this equilibrium is asymptotically stable if and only in $B<0$ and $B^{\prime}<0$. Hence, the non-corruption equilibrium $\left(n_{c}^{4}, g_{c}^{4}\right)=(0,0)$ is stable if the non-corrupt government practices appropriate fines and it has high re-election power.

Finally, we observe that the corruption and non-corruption equilibria can be simultaneously stable. When both are stable the other two boundary equilibria are unstable and the interior equilibrium is a saddle.

\section{Non-corrupt government with high re-election power and appropriate fines}

In this subsection, we assume that $B<0$ and $B^{\prime}<0$. Hence the non-corrupt government has high reelection power and uses appropriate fines. In this case the good equilibrium $\left.\left(n_{c}^{4}, g_{c}^{4}\right)\right)=(0,0)$ is always asymptotically stable.

- When $A>-B$ and $A^{\prime}>-B^{\prime}$ then $A+B>0$ and $A^{\prime}+B^{\prime}>0$. From these conditions the following inequalities are verified: $A>0, A^{\prime}>0,0<-\frac{B}{A}<1$, and $0<-\frac{B^{\prime}}{A^{\prime}}<1$, implying the existence of a mixed equilibrium in the interior of the unit square. In this case we also have that $\frac{B^{\prime} B}{A A^{\prime}}\left(B^{\prime}+A^{\prime}\right)(B+A)>0$, so the Hartman-Grobman theorem can be applied to the mixed equilibrium, yielding a saddle point. In this case the "bad" equilibrium and the "good" equilibrium without corruption are asymptotically stable. See Figure (1) for the general picture of the dynamics in this case.

This is a good example of ongoing spontaneous coordination. Note that this case corresponds to a social situation where:

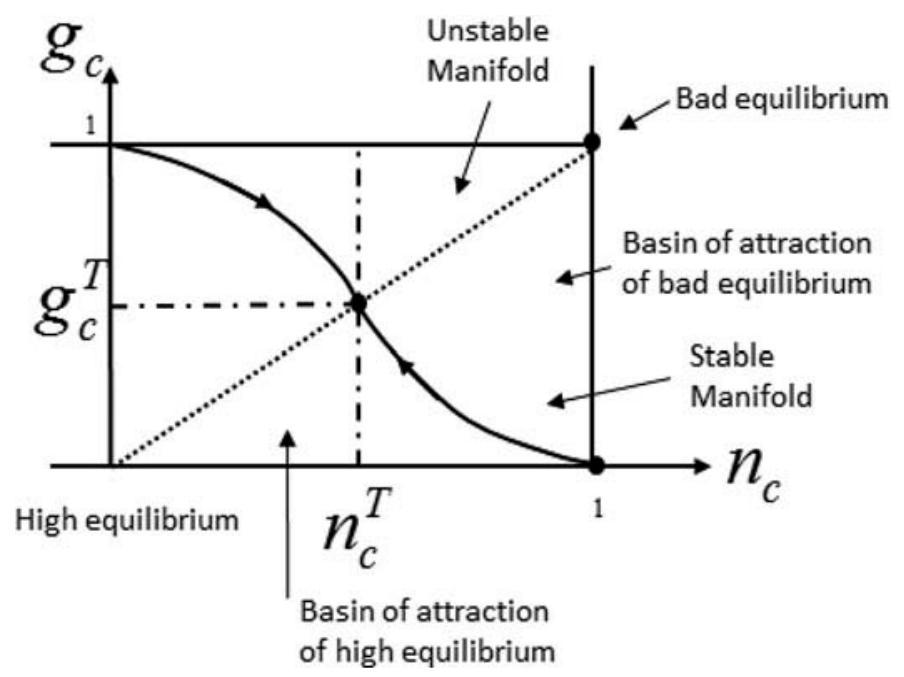

Figure 1. The dynamics of the system, with the basin of attraction of the equilibria and the mixed Nash equilibrium. 
(a) The amount $M$ of the fine imposed by a non-corrupt government to a corrupt official is relatively high, meaning that it is greater than the bribe $M_{c}$ the official takes from citizens, i.e., $M>M_{c}$.

(b) The inequality $M_{g^{\prime}}>M_{g}-M_{c}$ is verified. Recall that $M_{g}^{\prime}$ is the amount that an honest official must pay to a dishonest government to keep his place. This means that a corrupt government punishes honest behavior more than dishonest behavior.

(c) The government is inefficient to catch corrupts officials, or equivalently, $e$ is relatively high (relatively high costs to combat corruption).

(d) The non-corrupt government has high re-election power. This may be written as $V_{G_{c}} D_{i t}>N M_{g}^{\prime}-K P+\left(V_{G_{n c}}-V_{G_{c}}\right) q_{G_{n c}}$. This occurs if the index of intolerance is high enough, and the government is interested in being re-elected.

If the initial distributions of officers and government actions correspond with a point in the basin of attraction of the bad equilibrium, then officials and government have incentives to act in a corrupt way. Thus, the general levels of corruption will increase, and corruption becomes a self-enforcing mechanism over time. In this case corruption can be regarded as a social trap.

However, the basin of attraction of the "bad" equilibrium $\left(n_{c}^{1}, g_{c}^{1}\right)=(1,1)$ decreases when the interior equilibria gets close to the 'bad' equilibrium $\left(n_{c}^{1}, g_{c}^{1}\right)$, i.e., when $A+B$ and $A^{\prime}+B^{\prime}$ tends to zero. Hence, the basin of attraction of the 'good' equilibrium $\left(n_{c}^{4}, g_{c}^{4}\right)=(0,0)$ is large when the noncorrupt government's costs in fighting corruption are close to the non-corrupt government efficiency threshold, i.e., $e$ is close to $T_{2}$, and the corrupt government penalizes honest officials similarly to dishonest officials, i.e., $M_{g^{\prime}}$ close to $M_{g}-M_{c}$.

The cost efficiency $e$ can get closer to the threshold $T_{2}$ because of different reasons: (a) noncorrupt government is able to decrease the value of its efficiency cost to capture the corrupt officials; (b) the efficiency threshold $T_{2}$ rises due for instance to an increase in the index of intolerance, an increase in the valuation of re-election by a corrupt government, an increase in the probability of a non-corrupt government being re-elected, to the increase of the fine imposed by a non-corrupt government to a dishonest official, or an increase in the vote buying by part of the corrupt government.

Hence, the levels of corruption that were increasing can suddenly change if the degree of intolerance of citizens increases. If the government believes that this change in intolerance can take place then (depending also on the value that the government assigns to be re-elected), it may result in a change in the basin of attractions of the "good" and "bad" equilibria, making some paths that would initially evolve toward the "bad" equilibrium now evolve toward the "good" equilibrium. This possibility is supported in the following fact:

Remark 5 The basin of attraction of the bad equilibrium $\left(n_{c}^{B}, g_{c}^{B}\right)=(1,1)$ decreases when the degree of intolerance increases and/or the cost to capture the corrupt officials decreases.

Thus, the index of intolerance of citizens with respect to corruption, if high enough, and if the government is interested in being re-elected can play an important role at the time to control the controller acting as a servomechanism correcting the evolution of corruption. It acts as a barrier stopping corruption, since, under several circumstances, it can reverse a process of growing corruption. The higher it is, the more difficult it gets that corruptions grows and develops within the government. In Figure (2) we plot some trajectories of the system that exemplify the previous remark. For the same initial conditions with different model parameters, corresponding to an increase in the degree of intolerance, we see that initial conditions originally in the basin of attraction of the bad equilibrium are instead converging to the good equilibrium. This illustrates the shrinking of the basin of attraction of the bad equilibrium as the degree of intolerance grows. 

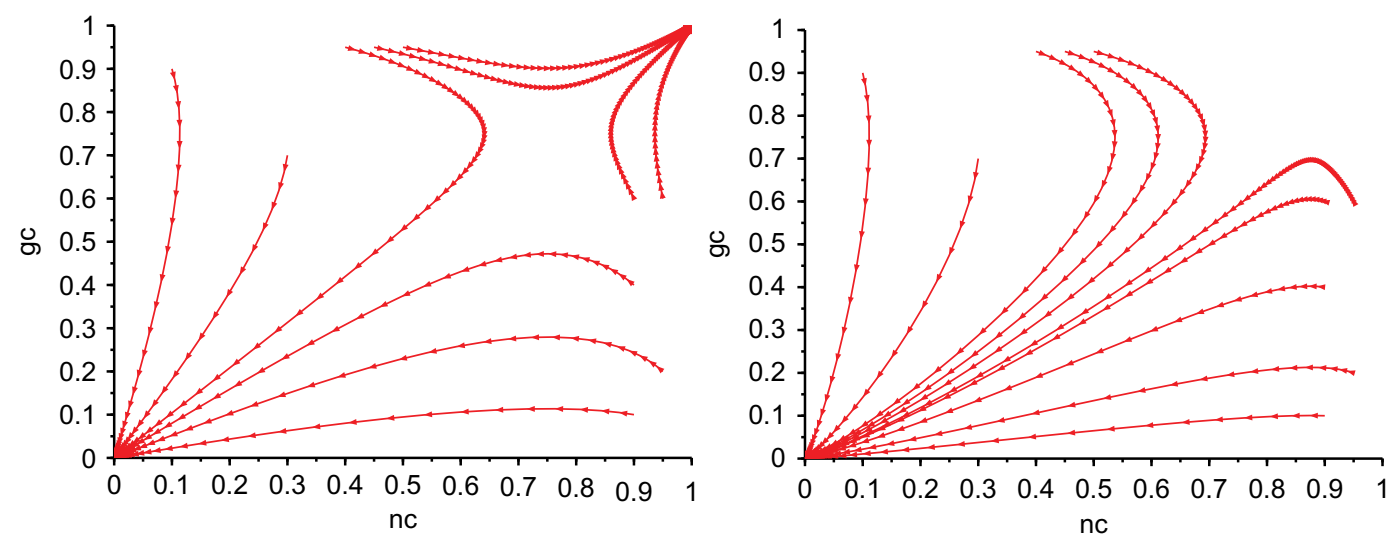

Figure 2. Some trajectories of the system for the same initial conditions with different parameters. Left-hand side: lower degree of intolerance. Right-hand side: higher degree of intolerance.

- Assuming that $A>-B$ and $A^{\prime}<-B^{\prime}$ it follows that $(A+B)>0,\left(A^{\prime}+B^{\prime}\right)<0$ then there is not a mixed Nash equilibrium because either $-\frac{B^{\prime}}{A^{\prime}}>1$ or $-\frac{B^{\prime}}{A^{\prime}}<0$. The "bad" equilibrium $\left(n_{c}^{1}, g_{c}^{1}\right)=(1,1)$ is a saddle point, as well as the equilibrium $\left(n_{c}^{2}, g_{c}^{2}\right)=(1,0)$, and the equilibrium $\left(n_{c}^{3}, g_{c}^{3}\right)=(0,1)$ is a repulsor. In this case there is a unique asymptotically stable dynamic equilibrium and this is the Nash equilibrium without corruption, i.e., $\left(n_{c}^{4}, g_{c}^{4}\right)=(0,0)$, with all the interior initial conditions being attracted to this point. See Figure (3). This conditions correspond to a strictly well ruled society.

- Assuming that $A<-B$ and $A^{\prime}<-B^{\prime}$ it follows that $(A+B)<0,\left(A^{\prime}+B^{\prime}\right)<0$ then the "bad" equilibrium is a repulsor, there is no mixed equilibrium, and there is a unique equilibrium that is asymptotically stable, that is the "good" equilibrium $\left(n_{c}^{4}, g_{c}^{4}\right)=(0,0)$, with all interior initial conditions being attracted to this point. The equilibria $\left(n_{c}^{2}, g_{c}^{2}\right)=(1,0)$ and $\left(n_{c}^{3}, g_{c}^{3}\right)=(0,1)$ are saddle points.

- Assuming that $A<-B$ and $A^{\prime}>-B^{\prime}$ it follows that $(A+B)\left\langle 0,\left(A^{\prime}+B^{\prime}\right)\right\rangle 0$. Then, there is no mixed equilibrium and the "bad" equilibrium $\left(n_{c}^{1}, g_{c}^{1}\right)=(1,1)$ is a saddle point as well as the

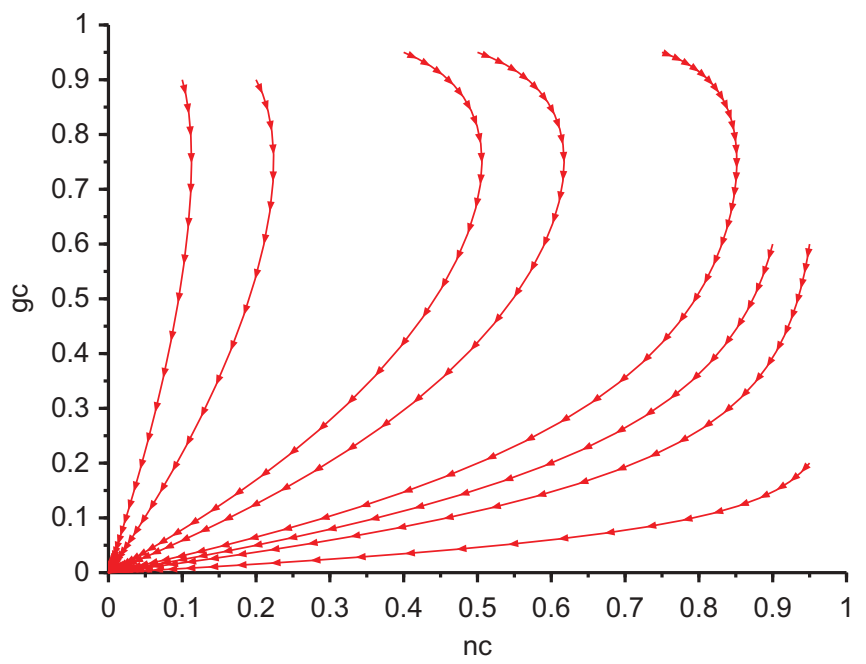

Figure 3. A well-ruled society. 
equilibrium $\left(n_{c}^{3}, g_{c}^{3}\right)=(0,1)$, and the equilibrium $\left(n_{c}^{2}, g_{c}^{2}\right)=(1,0)$ is a repulsor. The only asymptotically stable equilibrium is the "good" equilibrium $\left(n_{c}^{4} ; g_{c}^{4}\right)=(0,0)$, with all interior initial conditions being attracted to this point. Corresponds to the case of a well ruled society.

In case (2), we have that $A+B>0$ and there is no mixed Nash equilibrium. The assumptions are describing a political situation corresponding to: (a) a corrupt government penalizes honest officials more than dishonest officials; (b) an index of intolerance relatively high; and/or (c) a governmental elite with a high interest in being re-elected; and/or (d) the government is highly efficient in fighting corruption, i.e., low values of $e$. This corresponds to a well ruled society.

Note that the cases (2), (3) and (4) are mathematically similar, but from a social point of view they are very different. The quantity $A+B=M_{g^{\prime}}+\left(M_{c}-M_{g}\right)$ can not be negative except if $M_{g^{\prime}}<M_{g}-M_{c}$. Since normally, this inequality is not verified, cases (3) and (4), and other cases to be studied below, such as cases (5) and (7), are apparently paradoxical (see remark (4) for a consideration about this quantity being negative).

\section{Non-corrupt government with low re-election power and inappropriate fines}

In this subsection, we assume that $B>0$ and $B^{\prime}>0$. Hence the non-corrupt government has low reelection power and uses inappropriate fines.

- Assuming that $A<-B, A^{\prime}<B^{\prime}$ then the inequalities $(A+B)<0,\left(A^{\prime}+B^{\prime}\right)<0$ hold. This is a seemingly paradoxical situation, where both the "good" non-corruption equilibrium $\left(n_{c}^{4}, g_{c}^{4}\right)=$ $(0,0)$ and the "bad" corrupt equilibrium $\left(n_{c}^{1}, g_{c}^{1}\right)=(1,1)$ are repulsor and the mixed Nash equilibrium is a saddle point (see remark (4)). The equilibria $\left(n_{c}^{2}, g_{c}^{2}\right)=(1,0)$ and $\left(n_{c}^{3}, g_{c}^{3}\right)=$ $(0,1)$ are attractors, i.e., government prefers to be honest but officials prefer to be corrupt, or reciprocally, government prefers to be corrupt but officials prefer to be honest. Which one of these two situations occurs is initial condition dependent. In Figure (4) we plot some transition paths of the system. Depending on the initial condition, the transition path approach either $\left(n_{c}^{2}, g_{c}^{2}\right)=(1,0)$ or $\left(n_{c}^{3}, g_{c}^{3}\right)=(0,1)$. The exception is one initial condition that approaches the mixed equilibrium, since that initial condition lies on the stable manifold of the mixed

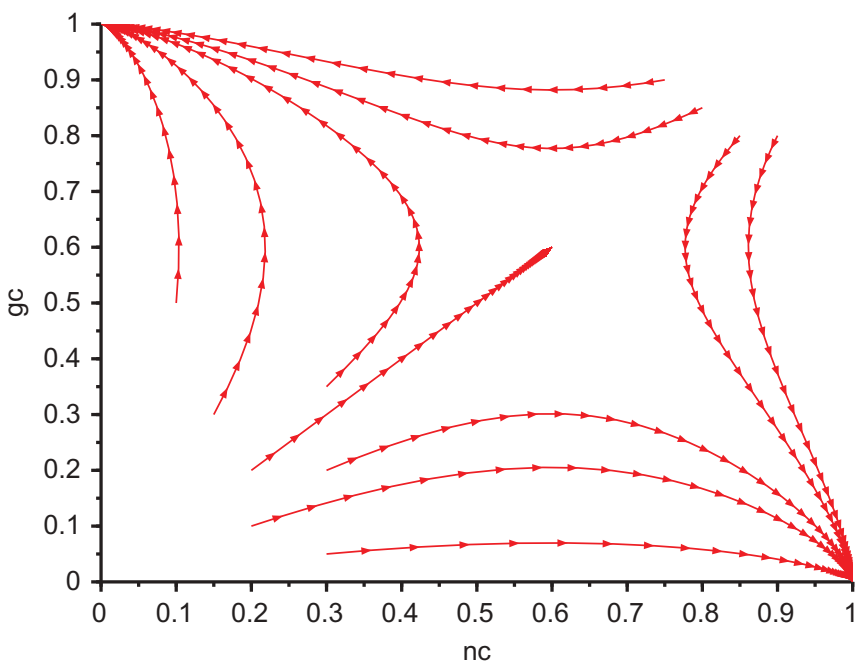

Figure 4. Different trajectories of the system for case (5). 
equilibrium. We observe that the stable manifold of the mixed equilibrium is a curve passing through the mixed equilibrium that connects the "bad" and the "good" equilibrium.

- Assuming that $A>-B, A^{\prime}<-B^{\prime}$ then $A+B>0$ and $A^{\prime}+B^{\prime}<0$. Hence, the corrupt government penalizes more honest officials than dishonest officials, i.e., $M_{g}<M_{g}-M_{c}(A+B<0)$, and the non-corrupt government is cost inefficient in fighting against corruption, i.e., $e>T_{2} / N\left(A^{\prime}+B^{\prime}>0\right)$. There is no mixed Nash equilibrium and the equilibrium $\left(n_{c}^{2}, g_{c}^{2}\right)=$ $(1,0)$ is the only equilibrium point that is asymptotically stable, and all initial conditions in the interior of the unit square are attracted to this equilibrium.

- Assuming that $A\left\langle-B, A^{\prime}\right\rangle-B^{\prime}$ then $A+B<0$ and $A^{\prime}+B^{\prime}>0$. There is no mixed Nash equilibrium and the equilibrium $\left(n_{c}^{3}, g_{c}^{3}\right)=(0,1)$ is the only equilibrium point that is asymptotically stable, and all initial conditions in the interior of the unit square are attracted to this equilibrium. This case is similar to the previous one when the initial conditions were in the basin of attraction of the equilibrium $\left(n_{c}^{3}, g_{c}^{3}\right)=(0,1)$.

In case (6) society is evolving to an equilibrium where officials prefer to be corrupt, even with an honest government. Our assumptions imply that governmental fines to punish corrupt behavior are relatively low, and that a non-corrupt government has low re-election power, because citizens perceive this government as a corrupt one. This case is mathematically analogous to the previous one, but very different in its social and political implications. This society evolves to an equilibrium where government is corrupt but officials prefer to be honest. We plot some trajectories of the system for case (6) in Figure (5). Summarizing, we can say that this case corresponds to a sociopolitical situation where government has a relatively high interest in being re-elected and so might try to prevent the spreading corruption. However, the government is unable to diminish corruption because of the government: (a) being focused on re-election; (b) being inefficient; or (c) practicing low fines imposed on corrupt officials.

The apparently paradoxical case (7) where the society could be evolving to an equilibrium where government is corrupt but officials prefer to be honest takes place when $A+B<0$ (as in cases (3), (4) and (5)). See remark (4).

- The strictly badly ruled society. Assuming that $B>0, B^{\prime}>0$ and $A>-B, A^{\prime}>-B^{\prime}$ then $A+B>0$ and $A^{\prime}+B^{\prime}>0$. In this case the "good" equilibrium $\left(n_{c}^{4}, g_{c}^{4}\right)=(0,0)$ is a repulsor and the corner

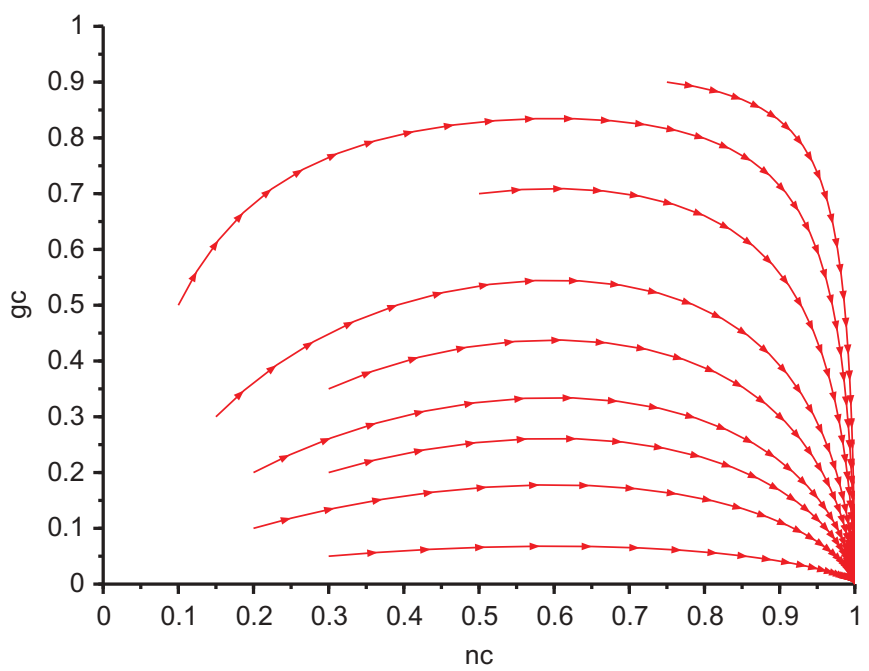

Figure 5. Some trajectories of the system for case (6). 


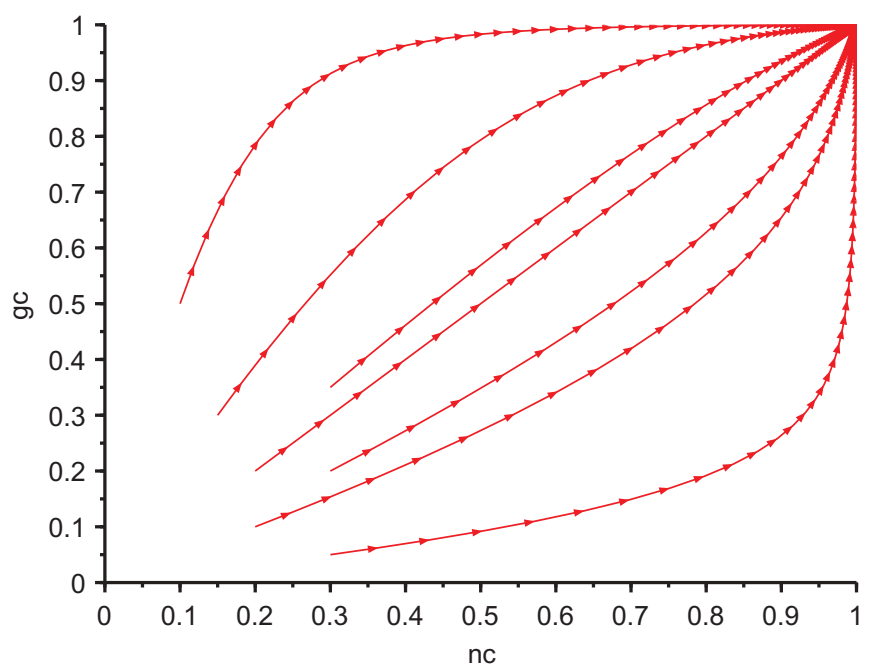

Figure 6 . The strictly badly ruled society.

equilibria $\left(n_{c}^{3}, g_{c}^{3}\right)=(0,1)$ and $\left(n_{c}^{2}, g_{c}^{2}\right)=(1,0)$ are saddle points. The only equilibrium point that is asymptotically stable is the "bad" equilibrium $\left(n_{c}^{1}, g_{c}^{1}\right)=(1,1)$, with all interior initial conditions being attracted to this point. We plot some trajectories of the system in Figure (6).

In case (8), we have an unruled society. The society is evolving toward full corruption both on the governmental level and on the officials' level, due to general inefficacy of government, low fines to punish corrupt officials, high costs to capture corrupt officials and because of low intolerance index. This extreme situation may occur in a dictatorship where the dictator confuses his own interests with national interests. However, it may occur in democratic societies where, for instance, citizens' perception of corruption is not clear, and where corruption is deeply rooted in society, almost as a cultural thing, very difficult to eradicate. The term Endemic Corruption has been used to designate this kind of phenomena. In this case, corruption becomes a cause of several social and economic ills.

\section{Corruption cycles}

Recent works show that the alternation in power can delay or stop processes of increasing corruption. However, this alternation can give place to a cyclical process of corruption, in which periods of increasing corruption alternate with periods in which it decreases. These periods are limited by the change of the ruler elite. Such is the case of Mexico in the period in which the alternation in power took place between the PRI (Partido Revolucionario Institucional) and the opposition party, PAN (Partido Acci $\tilde{A}^{3} n$ Nacional). While we are witnessing a first period in which corruption descends, then this process accelerates, growing until the moment when the PAN is replaced in power by its competitor, the PRI. From the new triumph of the PRI we witness a new process of restraint and subsequent expansion of the corruption process. See for instance (Soto \& Cortez, 2015) for a good study of cycles in Mexican politics. As we shall show the possibility of such cyclical process appear as a particular case of our model.

Let as consider now the case where $\frac{B^{\prime} B}{A A^{\prime}}\left(B^{\prime}+A^{\prime}\right)(B+A)<0$. Note that in this case HartmanGrobman's theorem doesn't apply, because the eigenvalues of the mixed equilibrium are purely imaginary numbers.

Let us consider the case where $B\left\langle 0, B^{\prime}\right\rangle 0$ and $A>-B, A^{\prime}<-B^{\prime}$. These inequalities imply that the bad equilibrium $\left(n_{c}^{1}, g_{c}^{1}\right)=(1,1)$ and the high equilibrium $\left(n_{c}^{4}, g_{c}^{4}\right)=(0,0)$ are saddle points. 

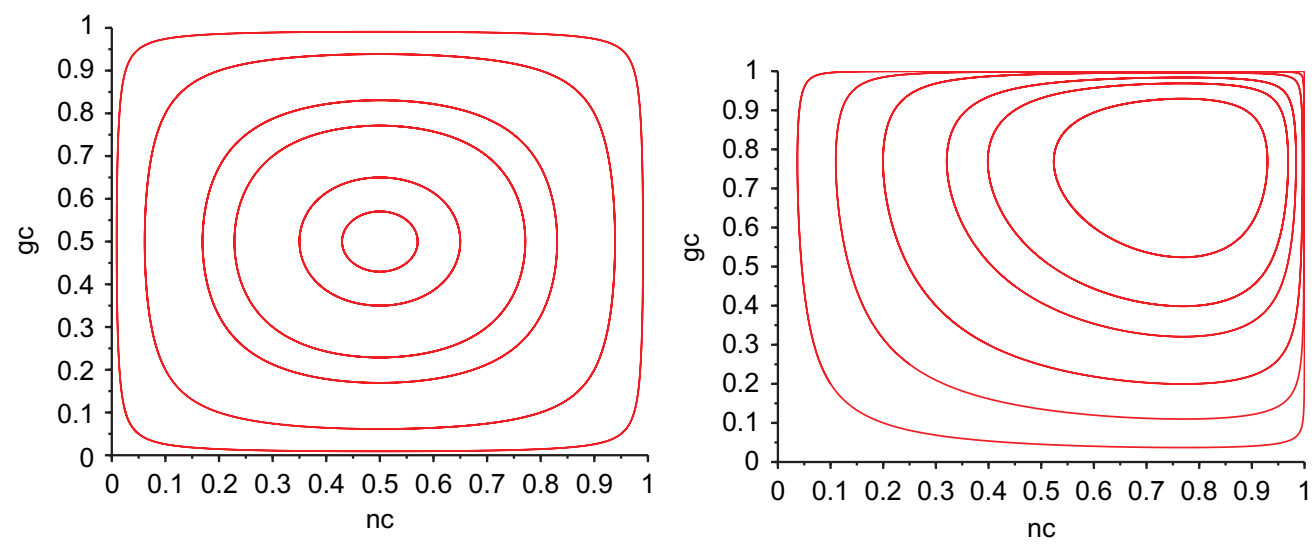

Figure 7. Some trajectories of the system (20) in the case of complex eigenvalues for different model parameters.

The corner equilibria $\left(n_{c}^{2}, g_{c}^{2}\right)=(1,0)$ and $\left(n_{c}^{3}, g_{c}^{3}\right)=(0,1)$ are also saddle points. These inequalities imply the existence of a mixed Nash equilibrium in the interior of the unit square, and by the previous formula, the eigenvalues of its linearization are purely imaginary numbers. It corresponds to cycles of growth and decline of corruption. Recall that in this case there are low costs to capture corrupt officials, resulting in high efficiency, and there are high fines to punish corrupt officials, but the intolerance index is low. This interplay between these quantities results in the appearance of periodic orbits, as shown in Figure (7). The mixed equilibrium is a focus. The rationale behind this situation is the following. The low index of intolerance causes an increase in government corruption, which in turn causes more officials to prefer to be corrupt. Facing an increasingly bigger number of corrupt officials, government decides to be less corrupt, taking advantage of low costs to capture corrupt officials and high fines, which in turn cause a disincentive for officials to become corrupt, thus increasing the number of honest officials. Hence, the overall levels of corruption in society have declined to the original levels so that the cycle restarts again. A similar situation with the appearance of periodic orbits occurs if $B>0, B^{\prime}<0$ and $A\left\langle-B, A^{\prime}\right\rangle-B^{\prime}$. This situation corresponds to high index of intolerance, but the efficiency costs are high and fines are low.

Periodic orbits may appear naturally if the intolerance index is a function of the percentage of corrupt agents. This index increases when the number of corrupt officials grows, and decreases as does the percentage of corrupt officials. The corrupt political elite feels the pressure of a high index of intolerance, possibly reducing its expected value in this case of re-election, because the probability of being re-elected is reduced. As a result, the government corruption is reduced, and government will seek to punish corrupt officials more severely. But by reducing the amount of corrupt officials, the index of intolerance decreases, and therefore the pressure on the government declines, again permitting an increase in governmental corruption and allowing for an increase in the number of corrupt officials, thus restarting the cycle of corruption.

\section{The transition paths}

For each time $t$ we say that the pair $\left(n_{c}(t), g_{c}(t)\right)$ defines the state of corruption of the society in time $t$. Thus, given the dynamical system (20) and an initial condition in time $t=t_{0}$ (i.e., an initial state of corruption), $\left(n_{c}\left(t_{0}\right), g_{c}\left(t_{0}\right)\right)=\left(n_{c_{0}}, g_{c_{0}}\right)$, we say that $\xi\left(\cdot,\left(n_{c_{0}}, g_{c_{0}}\right)\right) \rightarrow \Re^{2}$ is a solution of the dynamical system with such initial condition if and only if $\xi\left(t,\left(n_{c_{0}}, g_{c_{0}}\right)\right)$ verifies the system (20), and $\xi\left(t_{0},\left(n_{c_{0}}, g_{c_{0}}\right)\right)=\left(n_{c_{0}}, g_{c_{0}}\right)$. Classic theorems in the theory of differential equations show that once an initial condition is fixed, there is a unique solution for the differential equation and that the function 
$\xi(t, \cdot): \Re^{2} \rightarrow \Re^{2}$ is smooth, i.e., the solution of the dynamical system (20) is smooth with respect to initial conditions (see, for instance (Hirsch, Smale, \& Devaney, 2012)).

Definition 3 (The trajectory of corruption) Given the dynamical system (20) and an initial condition in time $t=t_{0}$, we define the trajectory of the corruption, as the set $\Gamma \subset \Re^{2}$ given by:

$$
\Gamma=\left\{\left(n_{c}(t), g_{c}(t)\right)=\xi\left(t,\left(n_{c}\left(t_{0}\right), g_{c}\left(t_{0}\right)\right)\right), \forall t \geq t_{0}\right\}
$$

Note that each trajectory defines a set of possible future states of corruption, i.e., for each initial condition, there is only one set of possible future states (since we do not consider shocks and stochastic effects in this work). So, the corruption in a given society, once the initial condition is fixed, evolves along a trajectory.

Definition 4 (The transition path) Given the dynamical system (20) and an initial condition the set of possible states for all $t>t_{0}$ will be called the transition path.

This transition path is given by the set of possible states $\left(n_{c}(t), g_{c}(t)\right)$ that represents the evolution of the corruption, from a fixed initial time $t=t_{0}$ until the system rests in a dynamical equilibrium. To obtain the possible transition path is equivalent to obtain the analytical solutions of the dynamical system (16). In general this is not possible, but in some particular cases it is. In the next section we consider some of these cases in which it is possible to obtain an analytical solution.

\section{Some particular cases}

In general, for a dynamical system, it is not possible to obtain a complete analytical solution, however, like we did in the previous sections in some cases it is possible to analyze the behavior of the solution close to each dynamical equilibrium. Certainly, to use this approach we need to assume that the parameters are given, or that they can be considered in a neighborhood of each one of this points as constant.

We consider here the case where $A=0$ or $A^{\prime}=0$. Note that $A=0$ is equivalent to $M_{g}=M+$ $M_{g^{\prime}}$ and $A^{\prime}=0$ is equivalent to $M_{g}+e=M+M_{g^{\prime}}$. To simplify the notation consider the case $V_{G_{c}}=V_{G_{n c}}=V_{G}$. In these cases, since the system (20) turns out to be uncoupled and its solution is relatively simple, fixed the initial condition in $t=0 n_{c}(0)$ and $g_{c}(0)$ we obtain the classical logistic solution.

$$
n_{c}(t)=\frac{n_{c}(0) e^{B t}}{\left(1-n_{c}(0)\right)+n_{c}(0) e^{B t}}, \quad \text { and } g_{c}(t)=\frac{g_{c}(0) e^{\left(M_{g}^{\prime}-K P\right) t+\int_{0}^{t} D_{i t} V_{G} d t}}{\left(1-g_{c}(0)\right)+g_{c}(0) e^{\left(M_{g}^{\prime}-K P\right) t-\int_{0}^{t} D_{i t} V_{G} d t}} .
$$

The evolution depends on the signs of $B$ and $\left(M_{g}^{\prime}-K P\right) t+\int D_{i t} V_{G} d t$.

Recall that $B=M_{c}-M$ and $B^{\prime}(t)=M_{g}^{\prime}-K P-V_{g} D_{i t}\left(n_{c}(t)\right)$. Then, $B<0$ if and only the value $M$ of the fine is high enough, i.e., if and only if $M>M_{c}$. Moreover, $B^{\prime}(t)<0$ if and only if the intolerance index $D_{i t}\left(n_{c}(t)\right)$ is for all time $t>0$ high enough i.e., $D_{i t} V_{g}\left(n_{c}(t)\right)>M_{g}^{\prime}-K P$.

More in detail, the following cases are possible and particularly interesting:

- If $B<0$ and for all time $B^{\prime}(t)=M_{g}^{\prime}-K P-V_{g} D_{i t}\left(n_{c}(t)\right)<0$ i.e., if $D_{i t}\left(n_{c}(t)\right)>\frac{1}{V_{G}}\left(M_{g}^{\prime}-K P\right)$ for all the $t>0$. The "good" equilibrium $\left(n_{c}^{4}, g_{c}^{4}\right)=(0,0)$ is globally asymptotically stable, and independently of the initial condition inside the unit square, society is evolving to a situation 
where officials and government prefer to follow an honest behavior, i.e., $g_{c}(t) \rightarrow 0$ and $n_{c}(t) \rightarrow$ 0 , so $\xi\left(t, n_{c_{0}}, g_{c_{0}}\right) \rightarrow(0,0)$, when $t \rightarrow+\infty$.

- If $B>0$ and is for al time $B^{\prime}(t)=M_{g}^{\prime}-K P-V_{g} D_{i t}\left(n_{c}(t)\right)>0$ i.e., if $D_{i t}\left(n_{c}(t)\right)<\frac{1}{V_{G}}\left(M_{g}^{\prime}-K P\right)$ for all the $t>0$.'bad' equilibrium $\left(n_{c}^{1}, g_{c}^{1}\right)=(1,1)$ is globally asymptotically stable, and independently of the initial condition inside the unit square, society is evolving to a situation where officials and government prefer to follow a corrupt behavior, i.e., $g_{c}(t) \rightarrow 1$, and $n_{c}(t) \rightarrow 1$, so $\xi\left(t, n_{c_{0}}, g_{c_{0}}\right) \rightarrow(1,1)$, when $t \rightarrow+\infty$.

- If $B>0$ and for all time $t B^{\prime}(t)<0$ then the equilibrium $\left(n_{c}^{2}, g_{c}^{2}\right)=(1,0)$ is globally asymptotically stable, i.e., $g_{c}(t) \rightarrow 0$, and $n_{c}(t) \rightarrow 1$, so $\xi\left(t, n_{c_{0}}, g_{c_{0}}\right) \rightarrow(1,0)$, when $t \rightarrow \infty$.

- If $B<0$ and for all $t B^{\prime}(t)>0$ then the equilibrium $\left(n_{c}^{3}, g_{c}^{3}\right)=(0,1)$ is asymptotically stable, i.e., $g_{c}(t) \rightarrow 1$, and $n_{c}(t) \rightarrow 0$, so $\xi\left(t, n_{c_{0}}, g_{c_{0}}\right) \rightarrow(0,1)$, when $t \rightarrow \infty$.

Note that the index of intolerance and the value that the current government assign to the reelection play a central role in the possible evolution of corruption. The greater his interest in reelection, the more he will tend to control corruption, at least that which directly affects voters. In all the above cases, the basin of attraction of the asymptotically stable equilibria is the whole interior of the unit square.

In the degenerate cases when $B=0$ or $B^{\prime}=0$, we have that, respectively, $n_{c}(t)$ or $g_{c}(t)$ is constant.

\section{The role of the index of intolerance revisited}

In some cases, corruption can be considered as a social trap (Rothstein, 2005). Under several circumstances, the "bad" equilibrium is asymptotically stable. In this case, if the initial distribution of corrupt officials and government's corrupt acts are in the basin of attraction of this equilibrium, neither official nor the government have incentives to act in a non-corrupt way. It is in this sense that we consider the corruption as a self reinforcing mechanism. Corrupt actions by a party encourage corrupt actions by the other. If everybody is corrupt, nobody wants to be honest. To be corrupt is the rational way, because under these initial conditions, the expected value of this behavior is higher than the expected value of the non-corrupt behavior. Under this prospect, corruption looks like a sticky problem that can not be changed for internal agents. This grim prospect is analyzed in several works. See for instance (Rothstein, 2005) and (Kornai, 2000). However, the degree of intolerance of citizens to corruption plays an important role to deter corruption. In these cases where corruption has advanced in different areas of society, neither the alternating power, not even popular participation, may be a guarantee against corruption. A corrupt ruler elite can buy the vote of hopeless citizens. In these cases, when the annoyance of citizens over corruption is high enough, the process can be reversed as we have seen above. This is precisely what the Index of Intolerance measures. The recent events in Brazil show the evolution of a society toward a low equilibrium, in which corruption seems to reach the different political elites, as well as officials, and where the high degree of nonconformity of citizens restrains a given party elite who appears as an accomplice of corrupt acts and ends up imposing another political group in government. The high degree of corruption of the different political sectors calls into question the possible curbing of the evolution of corruption. However, the high degree of intolerance of corruption demonstrated by citizens will force the political sectors now in the government to take precautions, if they intend to remain in power or even in some cases avoid imprisonment or prosecution for corruption offences, after some possible (even probable) subsequent changes in the forces in power (see Brazil Corruption Report - Business AntiCorruption Portal in (Brasil Corruption Report, 2017) and (Wikipedia)). See also the discussion about Mexican politics in (Soto \& Cortez, 2015) and in the preceding section on corruption cycles. There are examples of success in deterrence of corruption, for instance the cases of 
Singapore and Honk Kong (see [Root, H.]). These examples show that only when the rate of intolerance to corruption is high these processes of increasing corruption can be stopped.

Now consider that the intolerance index is an increasing and convex function of the number of corrupt officials and assume that $V_{G_{n c}}=V_{G_{c}}=V_{G}$. Then there exist $n_{c \max }$ such that for all $n_{c}(t)>n_{c \max }$ the inequality

$$
V_{G} D_{i t}\left(n_{c}(t)\right)>\left[n_{c}(t) N\left(M_{g}-M_{g}^{\prime}-M+e\right)+M_{g}^{\prime}-K P\right]
$$

or equivalently

$$
D_{i t}\left(n_{c}(t)\right)>\frac{1}{V_{G}}\left[n_{c}(t) N\left(M_{g}-M_{g}^{\prime}-M+e\right)+M_{g}^{\prime}-K P\right]
$$

holds, then taking in to account Eq. (13) it follows that $E\left(G_{n c}\right)>E\left(G_{c}\right)$. Note that this $n_{\text {cmax }}$ will be the maximum percentage of corrupt officials that a government interested in being re-elected can tolerate, and corresponds to the point where the convex function $y=D_{i t}\left(n_{c}\right)$ intercepts the straight line $y=\frac{N}{V_{G}}\left(M_{g}-M_{g}^{\prime}-M+e\right) n_{c}+\frac{1}{V_{G}}\left(M_{g}^{\prime}-K P\right)$. So, a rational elite ruler must be receptive to the unhappiness of citizens if she has some interest in being re-elected.

Note that under the hypothesis of our model, it is natural to assume that the Intolerance Index grows with the amount of corrupt officials, because citizens perceive the corruption through the actions of the officials. When the amount of corrupts officials increases, the perception of corruption increases, increasing the intolerance of the population. However in future works it will be necessary to complete this index, considering other sources of information for citizens, for instance the press, rumors, and investigations about vote buying, about government corruption and other aspects.

\section{Conclusions}

As it is well known, many politicians and ruling elites across the world and from the whole of the political spectrum are currently involved in processes of corruption. Is it possible to deter this process? To give an answer to this question is the main concern of this article. In order to do this, we considered an evolutionary model, where the political agents (considered as players of a game in normal form) compare their respective expected payoffs, and they choose their strategies according to their average performances and the most profitable behaviors end by prevailing. Hence the replicator's dynamics appear as a natural mathematical tool to describe the evolution of corruption inside a society.

We first obtained that corruption corrupts, so that corruption is a self-reinforcing mechanism (see Proposition (1). When the degree of intolerance is relatively low and the political elite in the government has good prospects of being re-elected and a large interest in gain immediate benefits, the country can be in a corruption trap, i.e., a self-reinforcing mechanism where corruption generates more corruption.

We constructed an evolutionary version of the game by means of the usual replicator dynamics. The dynamics have five equilibria, four of them corresponding to pure strategies where both government and officials are corrupt, where both are non-corrupt, where only government is corrupt and officials are not and where government is honest and officials are corrupt. The other equilibrium is a mixed strategy where government and officials chose to be corrupt with a given probability. We then did the stability analysis of these equilibria according to the characteristics of government and officials. These characteristics are: the fines practiced by the corrupt government on corrupt officials, that may be appropriate or not; the re-election power of a non-corrupt government (i.e., its chances of being maintained in power); the penalizations that a corrupt government practices in honest and dishonest officials; the efficiency of a non-corrupt government in fighting corruption.

We obtained that the mixed interior equilibrium corresponding to a mixed strategy is a saddle point. It may be a focus around which the solutions oscillate, corresponding to cycles of corruption 
over time. They arise when there is cost efficiency and high fines but re-election power is low. In the other cases, the mixed equilibrium is such that its stable manifold separates two different outcomes. In one case, it separates initial conditions that will lead to a general increase in corruption levels and those that will lead to a general decrease in corruption. In the other case, it separates between conditions that will lead to an increase in government corruption and a decrease of corruption by officials and those that will lead to a decrease in government corruption and an increase in officials' corruption.

These two asymmetrical situations where corruption increases in one of the agents and decreases in the other may be interpreted as situations usually observed in dictatorial regimes. The first one generally corresponds to a political elite that benefits from corruption that is practically confined to the elite itself, together with an efficient censorship system and control of its employees. This corresponds in our model to the punishment of officials for being corrupt and breaking the rules. The other generally corresponds to a situation where there is a de facto government of the officials sustained by a power above the law, with a complacent de jure government.

We have that not all situations are compatible with each other. When the non-corruption good equilibrium or the corruption bad equilibrium are stable then the asymmetrical equilibria described above can't be stable, and vice-versa. More precisely, when there are appropriate fines practiced by the government that has high re-election power, then only the "good" non-corruption equilibrium and the "bad" corruption equilibrium may be stable. If the costs to catch corrupt officials are high, then both are stable and the mixed equilibrium separates conditions leading to them. So for some initial conditions the society may be in a social trap that increases the general levels of corruption. On the other hand, when re-election power is low and fines are inappropriate, then the "good" noncorruption equilibrium is never stable. Furthermore, in this case, when there are high penalties for corrupt officials by a corrupt government (see remark 4), the equilibrium where government is corrupt and officials honest is stable. When penalties are higher for corrupt officials, then either the equilibrium of the government of the officials is stable or the "bad" equilibrium is stable, depending on whether there is cost efficiency or inefficiency, respectively.

For the case where the country may be in a social trap with increasing levels of corruption, an external event may be a necessary condition for the country to leave this trap. This social trap may escape any self-monitoring mechanism, and then there is no way to control the controller. However, if the ruling elite has some interest in the re-election this self-reinforcing mechanism can be weakened or broken by a high enough degree of intolerance to corruption by the citizens. The degree of intolerance to corruption plays an important role to make the government fulfill the role that society has assigned it, even when some of its members are attracted by the individual benefits that corruption offers. Even in situations where corruption tends to expand, if the intolerance index has an abrupt change, the regressive process can be reversed ${ }^{6}$. Moreover, we also have seen that cyclical processes may appear in which periods of diminishing corruption are followed by periods of increasing corruption. However, if the corruption index is not high enough, corruption can be selfsustaining even if different elites alternate in power, yielding cycles of corruption or because of the existence of electoral processes where purchasing of votes by corrupt governments is significant.

Thus, how to maintain a high index of intolerance to corruption is a fundamental question. Responding correctly to this question may be the key to avoiding increasing corruption and cyclical corruption processes. The index of intolerance to corruption depends on the citizen's perception of corruption and decreases when the number of corrupt acts decreases. Since this index reflects a perception of the citizens it can be exploited by a ruling elite to gain personal benefits from corrupt acts. Furthermore, it can be exploited by means of other political and economical mechanisms not

\footnotetext{
${ }^{6}$ Recent events in South Korea, where citizens unanimously reacted to the corrupt practices of Prime Minister Park Geun-hye suggest that, if the Index of Intolerance of citizens to Corruption is high enough, it is possible to exert political pressure that can maybe result in stopping the growth of corruption. See http://www.abc.ne t.au/news/2016-11-15/south-korea-park-geun-hyehopes-political-crisis-be-contained/8024978.
} 
included in the index of intolerance we introduced, and not addressed in this article. Perhaps this is one of the most important shortcomings of the index we proposed. Another issue is the media pressure about corruption and the very relevant aspect of corruption perception in the society. We plan to address some of these in future works.

Confirmation of results by empirical testing and statistical methods is surely a very important issue. However, this was not our goal in this work. We focused instead on a game theoretical model of conflict between several levels of controllers, with the objective of obtaining some insight and a game theoretic and evolutionary reasoning for the question posed in the title of this work, and to capture some essential features of this conflict between over the question of controlling honest vs. corrupt behaviors in employees of the central government (that may be lured into dishonest behavior). There have been some previous approaches to corruption via game theory, as for instance in (Accinelli et al., 2014), focused on the problem of environment protection. However, as far as we know, our game theoretic approach to corruption by means of the problem of controlling the controller is new. Surely empirical testing of the results using some of the quantities introduced in our game is an important issue. However, it should be noted that this work points toward a game theoretical and dynamical approach and methodology that drew some fundamental features of the conflict between agents, so that it might require significant changes to the model to proceed to some kind of empirical testing. We will try to address this in future works. It should also be noted that there are statistical studies and case studies in specific countries yielding results that go in different directions. For example, see the introduction of (Soto \& Cortez, 2015) and the references therein about corruption and economic growth. Mauro (1995) has shown the negative effects of corruption on investment and economic growth, while (Egger \& Winner, 2005) show the positive correlation of corruption and direct foreign investment. Some studies conclude that corruption is a cyclical phenomena, associated with alternation in power of the ruling elites acts (see (Soto \& Cortez, 2015)). Others, in which citizen participation reduces general corruption levels (see (Root, 1996), where South-Eastern Asian countries are analyzed). Thus, our model gives a game theoretical background to these different situations, because starting from different initial conditions, we may obtain different evolutionary outcomes even when the electoral processes are similar, the difference being on the characteristic parameters of societies.

We can say that we have given at least a partial answer to the question that motivated this article and the answer is quasi-optimistic, because it seems possible to control the controller. The citizens are the main protagonists in this control process, although, certainly, for citizen participation to be effective, a high index of intolerance to corruption is required.

Summarizing, in this article we gave a first step to recognize the possibility of fight with success against the corruption and in the knowledge of possible trajectories of the evolution of a corruption process. However, as we said in section 7 to obtain the analytical solution of the dynamical system is generically not possible, but we can obtain some approximation using numerical methods and do stability and qualitative analysis of the trajectories of the system.

The model can be improved by further studying on the characteristics of the parameters considered. For instance, the degree of intolerance of citizens, that may be modeled as depending on other political, social, and economic variables. It will be necessary to consider also cross terms and the corresponding nonlinear effects and to study other types of dynamics, for instance, the role of the imitative behavior (see (Accinelli \& Sánchez Carrera, 2012)). Other accesses to information, like the press and modern media, that can exert relevant influence in the performance of the index of intolerance should also be incorporated in future developments of the model.

\section{References}

Accinelli, E., Policardo, L., \& Sánchez Carrera, E. J. (2014). On the dynamics and effects of corruption on environmental protection. a chapter in A. A. Pinto, \& D. Zilberman (eds.), Modelling, dynamics, optimization and bioeconomics I (Vol. 73, pp. 23-41). Cham: Springer Proceedings in Mathematics \& Statistics. 
Accinelli, E., \& Sánchez Carrera, E. J. (2012). Corruption driven by imitative behaviour. Economics Letters, 117(1), 8487. doi:10.1016/j.econlet.2012.04.092

Accinelli, E., \& Sánchez Carrera, E. J. (2015). Corruption, Inequality, and Income Taxation. J.-P. Bourguignon, R. Jeltsch, A. A. Pinto, \& M. Viana (eds.), Dynamics, games and science published by Springer-Verlag in CIM Series in Mathematical Sciences (Vol. 1, pp. 1-16). Germany: Springer-Verlag.

Allen, H. W., \& Allen, K. W. (1981). Vote fraud and data validity. In J. Clubb, W. Flanigan, \& N. Zingale (eds.), Analyzing electoral history: A guide to the study of American voter behavior Beverly hills: Sage publications (pp. 153195). Beverly Hills, California: Sage Publications.

Becker, G. (1983). A theory of competition among pressure groups for political influence. The Quarterly Journal of Economics, 98(3), 371-400. doi:10.2307/1886017

Brasil Corruption Report. (2017). Retrieved from http://www.business-anti-corruption.com/country-profiles/brazil.

Campbell, S. V. (2013). Perception is not reality: The FCPA, Brazil, and the mismeasurement of corruption. Minnesota Journal of International Law, 22(1), 247-281.

Corruption in Brazil. (2017). From Wikipedia, the free encyclopaedia, April. Retrieved from https://en.wikipedia.org/ wiki/Corruption_in_Brazil

Egger, P., \& Winner, H. (2005). Evidence on corruption as an incentive for foreign direct investment. European Journal of Political Economy, 21(4), 932-952. doi:10.1016/j.ejpoleco.2005.01.002

Grego, J. (2013, November). A history of parliamentary elections and electioneering in the old days. originally published in 1886. Re-edited by Nabu Press. Retrieved from https://archive.org/details/historyofparliam00greg

Grossman, G. M., \& Helpman, E. (1994, September). Protection for sale. The American Economic Review, 84(4), 833-850.

Hirsch, M., Smale, S., \& Devaney, R. (2012). Differential equations, dynamical systems, and an introduction to Chaos (3rd ed.). Oxford: Elsevier Ltd.

Hurwicz, L. (2007). But who will guard the guardians?. Nobel Prize Lecture. Retrieved from http://www.nobelprize.org/ nobel_prizes/economic-sciences/laureates/2007/hurwicz_lecture.pdf

Jain, A. K. (2001). Corruption: A review. Journal of Economics Surveys, 15(1), 1-51. doi:10.1111/1467-6419.00133

Juvenal. (1991). "The satires", Translation: Niall Rudd, Oxford's world classics. Oxford, NY: Clarendon Press. The original Latin text is available in. and an English translation is available in http://www.tertullian.org/fathers/ \#Juvenal Retrieved from http://www.thelatinlibrary.com/juvenal.html

Kornai, J. (2000). Hidden in an envelope. Gratitude payments to medical doctors in Hungary. New York, NY: Budapest Collegium Budapest Institute for Advanced Studies.

Lessig, L. (2011). Republic lost: How money corrupts congress - and a plan to stop it (ISBN-13: 978-0446576437). Twelve.

Lui, F. T. (1985, August). An equilibrium queuing model of bribery. Journal of Political Economy, 93(4), 760-781. doi: $10.1086 / 261329$

Lui, F. T. (1986, November). A dynamic model of corruption deterrence. Journal of Public Economics, 31(2), $215-236$. doi:10.1016/0047-2727(86)90019-8

Mauro, P. (1995, August). Corruption and growth. The Quarterly Journal of Economics, 110(3), 681-712. doi:10.2307/ 2946696

Mishra, A. (2006). Persistence of corruption: Some theoretical perspectives. World Development, 34(2), February, 349358. Elsevier. doi: 10.1016/j.worlddev.2005.03.010

Plato. (2008). "Republic", translator: Benjamin Jowett, Ebook produced by Sue Asscher and David Widger, project Gutenberg. Retrieved from http://www.gutenberg.org/ebooks/1497

Root, H. (1996). Small countries, big lessons: Governance and the rise of East Asia. Hong Kong: Oxford University Press.

Rose-Ackerman, S. (1975, February). The economics of corruption. Journal of Public Economics, 4(2), 187-203. doi:10.1016/0047-2727(75)90017-1

Rose-Ackerman, S. (1978). Corruption. A study in political economy. New York: Academic Press.

Rothstein, B. (2005). Social traps and the problem of trust. Cambridge: Cambridge University Press.

Sah, R. (1987). Persistence and pervasiveness of corruption. Conference on Political Economy: Theory and Policy Implications, Washington, DC. World Bank.

Seligson, M. (2002). The impact of corruption on regime legitimacy: A comparative study of four Latin American countries. The Journal of Politics, 64(2), 408-433. doi:10.1111/1468-2508.00132

Shleifer, A., \& Vishny, R. (1993). Corruption. The Quarterly Journal of Economics, 108(3), 599-617. doi:10.2307/ 2118402

Soto, I. M., \& Cortez, W. (2015). The impact of political alternation on corruption in Mexico. Revista De Ciencia Política, 35/2, 371-392. Available in http://www.redalyc.org/articulo.oa?id=32442271006

Thompson, D. (1995). Ethics in congress: From individual to institutional corruption. Washington, DC: Brookings Institution Press.

Weibull, W. J. (1995). Evolutionary game theory. Cambridge, MA: The MIT Press. 